\title{
Safety Evaluation of Polyethylene Glycol (PEG) Compounds for Cosmetic Use
}

\author{
Hyun-Jun Jang', Chan Young Shin ${ }^{2}$ and Kyu-Bong Kim ${ }^{1}$ \\ ${ }^{1}$ College of Pharmacy, Dankook University, Cheonan, Korea \\ ${ }^{2}$ Department of Neuroscience, School of Medicine, Konkuk University, Seoul, Korea
}

(Received June 10, 2015; Revised June 17, 2015; Accepted June 29, 2015)

\begin{abstract}
Polyethylene glycols (PEGs) are products of condensed ethylene oxide and water that can have various derivatives and functions. Since many PEG types are hydrophilic, they are favorably used as penetration enhancers, especially in topical dermatological preparations. PEGs, together with their typically nonionic derivatives, are broadly utilized in cosmetic products as surfactants, emulsifiers, cleansing agents, humectants, and skin conditioners. The compounds studied in this review include PEG/PPG-17/6 copolymer, PEG-20 glyceryl triisostearate, PEG-40 hydrogenated castor oil, and PEG-60 hydrogenated castor oil. Overall, much of the data available in this review are on PEGylated oils (PEG-40 and PEG-60 hydrogenated castor oils), which were recommended as safe for use in cosmetics up to $100 \%$ concentration. Currently, PEG-20 glyceryl triisostearate and PEGylated oils are considered safe for cosmetic use according to the results of relevant studies. Additionally, PEG/PPG-17/6 copolymer should be further studied to ensure its safety as a cosmetic ingredient.
\end{abstract}

Key words: Polyethylene glycol (PEG), PEG compound, Safety evaluation

\section{INTRODUCTION}

Polyethylene glycols (PEGs) are composed of polyether compounds repeating ethylene glycol units according to the constituent monomer or parent molecule (as ethylene glycol, ethylene oxide, or oxyethylene) (Fig. 1). Most PEGs are commonly available commercially as mixtures of different oligomer sizes in broadly- or narrowly-defined molecular weight (MW) ranges. For instance, PEG-10,000 typically designates a mixture of PEG molecules $(n=195$ to 265) having an average MW of 10,000. PEG is also known as polyethylene oxide (PEO) or polyoxyethylene (POE), with the three names being chemical synonyms. However, PEGs mainly refer to oligomers and polymers with molecular

Correspondence to: Kyu-Bong Kim, College of Pharmacy, Dankook University, 119 Dandae-ro, Cheonan, Chungnam 330-714, Korea

E-mail: kyubong@dankook.ac.kr

Abbreviation: CIR, Cosmetic Ingredient Review; IgG, immunoglobulin G; PEGs, polyethylene glycols; PEO, polyethylene oxide; POE, polyoxyethylene; PPG, polypropylene glycol; S-D, Sprague-Dawley.

This is an Open-Access article distributed under the terms of the Creative Commons Attribution Non-Commercial License (http:// creativecommons.org/licenses/by-nc/3.0) which permits unrestricted non-commercial use, distribution, and reproduction in any medium, provided the original work is properly cited. masses below 20,000 g/mol, while PEOs are polymers with molecular masses above 20,000 g/mol, and POEs are polymers of any molecular mass. Relatively small molecular weight PEGs are produced by the chemical reaction between ethylene oxide and water or ethylene glycol (or other ethylene glycol oligomers), as catalyzed by acidic or basic catalysts. To produce PEO or high-molecular weight PEGs, synthesis is performed by suspension polymerization. It is necessary to hold the growing polymer chain in solution during the course of the poly-condensation process. The reaction is catalyzed by magnesium-, aluminum-, or calcium-organoelement compounds. To prevent coagulation of polymer chains in the solution, chelating additives such as dimethylglyoxime are used (1).

PEGs, together with their derivatives, do not have definite chemical entities, rather, they are compound mixtures having different chain lengths. PEGs are used in cosmetics "as is" or in combination with their derivatives in which their 2 terminal primary hydroxyl groups can create mono-, di- and poly-esters, amines, ethers and acetals. Furthermore, PEGs can create additional compounds and complexes through a reaction in their ether bridges. Overall, PEG derivatives may include PEG ethers (e.g. laureths, ceteths, ceteareths, oleths, and PEG ethers of glyceryl cocoates), PEG fatty acids (e.g. PEG laurates, dilaurates, stearates, and distearates), PEG castor oils, PEG amine 
HO<smiles>CCCO</smiles>

Ethylene glycol

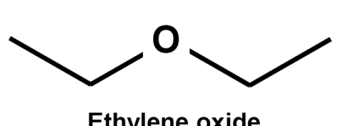

Ethylene oxide

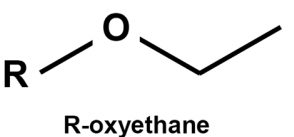

R-oxyethane

Diethylene glycol<smiles>OCCOCCO</smiles>

Triethylene glycol

HO<smiles>CCCOCCOCCO</smiles>

Tetraethylene glycol $\mathrm{HO}$<smiles>CCCOCCO</smiles>

Poly(n)ethylene glycol

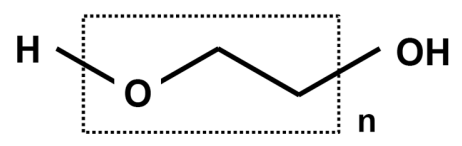

Fig. 1. Polimerization of ethylene glycol.

ethers (PEG cocamines), PEG propylene glycols, and other derivates (e.g., PEG soy sterols and PEG beeswax). Since many PEG types are hydrophilic, they are favorably used as penetration enhancers, especially in topical dermatological preparations (2). Polyethylene glycols (PEGs) and their derivatives are widely used in cosmetics as surfactants, cleansing agents, emulsifiers, skin conditioners, and humectants.

Adding to their use in cosmetics, many PEG compounds also have other applications. Available information from these uses is included in this assessment where relevant. In the pharmaceutical industry, for instance, they are used as ointment bases or vehicles for drugs in capsules, tablet and pill binders, suppositories, and liquid prescriptions; and in veterinary drugs as part of parenteral, topical, ophthalmic, oral, and rectal preparations. Further various applications were found in soaps and detergents, wood preservation, printing, chemical mixtures, as well as in industries that produces textiles, leather, plastics, resins, paper, ceramics, glass, rubber, petroleum, and metal. Polyoxyethylene sorbitan esters (polysorbates) and polyethylene glycol, with an average molecular weight of 6,000, are permitted as food additives in various food products $(3,4)$.

In previous studies, PEGs and various PEG compounds have been reviewed and assessed well to be concluded as relatively safe for use in cosmetics under the present conditions of intended use $(3,5,6)$. However, all PEG compounds were not covered in the previous studies due to their wide variety, and the introduction of new entities currently used in cosmetics suggests supplementary evaluation. Thus, it is essential to continuously monitor the safety and risks of PEG-derived products being exposed to consumers using cosmetic products to ensure that no potential health threats will arise, especially when used extensively and chronically. In this review, we searched for and enumerated the PEG polymers and their derivatives that are used in cosmetics (Table 1) in order to evaluate the safety of their application according to the currently available information in the literature.

\section{PEG COMPOUNDS FOR COSMETIC USE}

PEG/PPG-17/6 copolymer. PEG/PPG-17/6 copolymer is a randomly produced chemical comprised of an average of 17 ethylene glycol repeats and 6 propylene glycol repeats (7). This mixture does not have a specific CAS number, rather, it is found to be included in the generic CAS number 9003-11-6, belonging to the general group of "poloxamers". A cosmetic ingredient review regarding alkyl PEGPPG ethers has been conducted, however it was not specified whether PEG/PPG-17/6 copolymer is a related mixture based on the given list (8). Accordingly, little is known about the toxicological properties of PEG/PPG-17/6 copolymer and thus, studies reflected in this review may be 


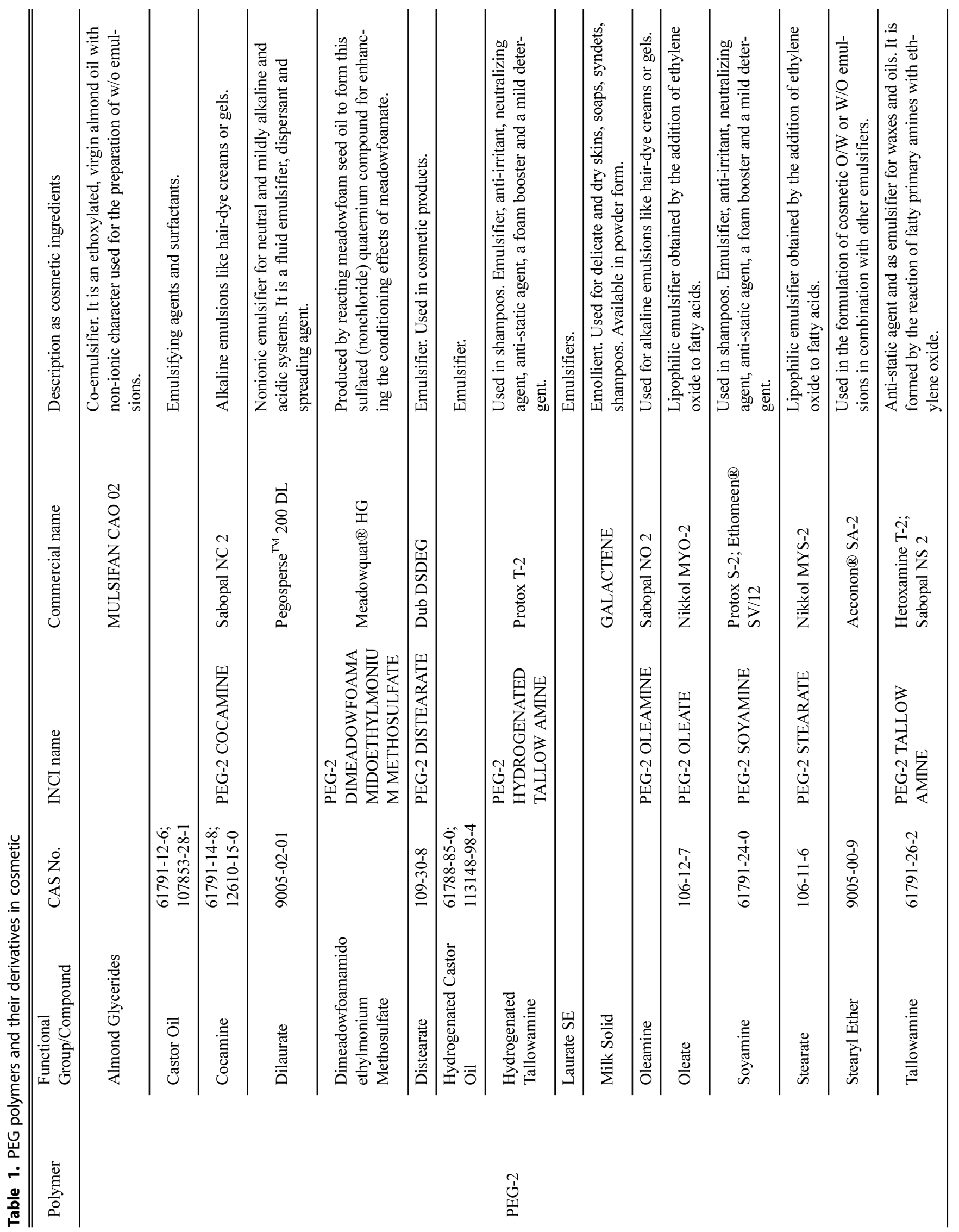




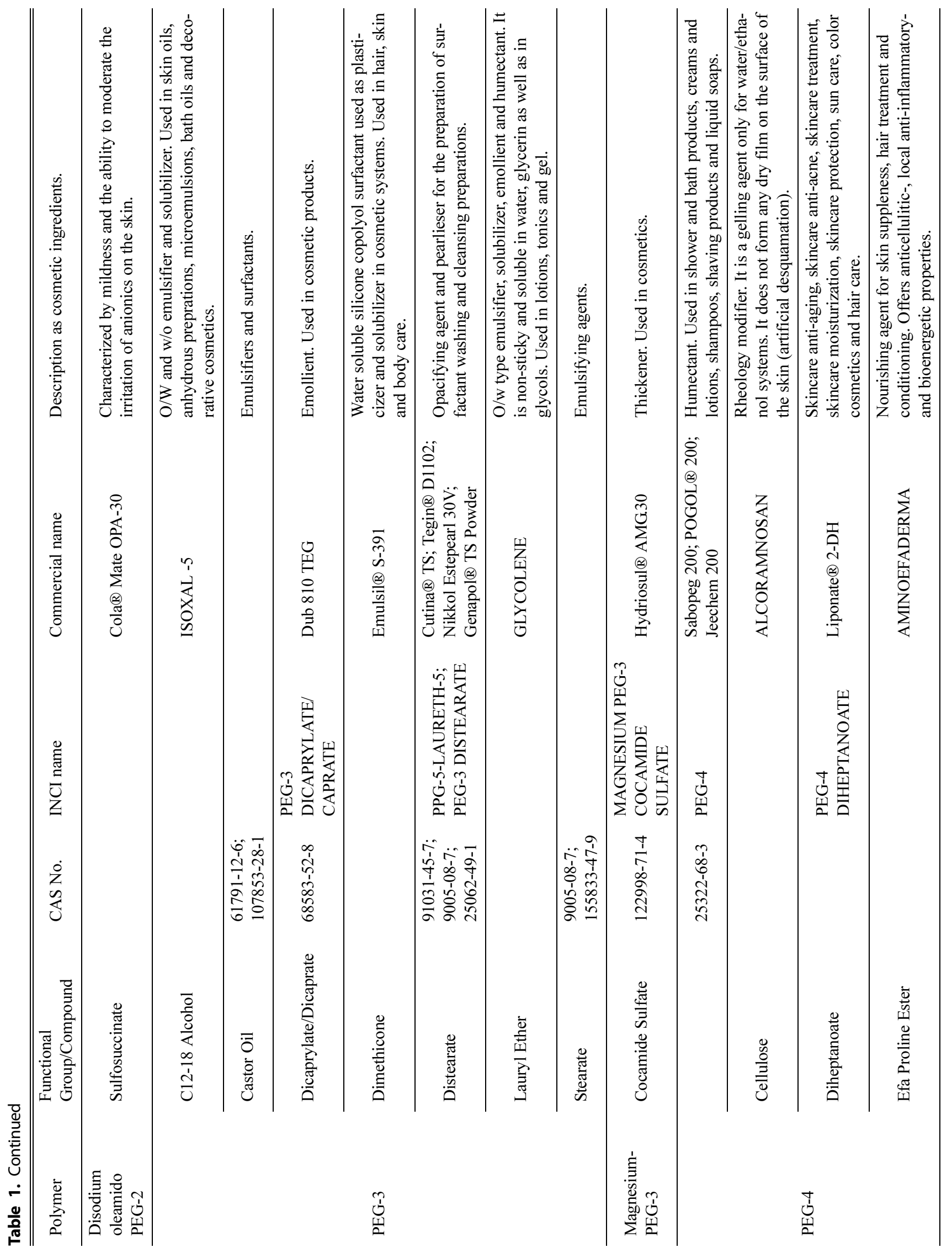




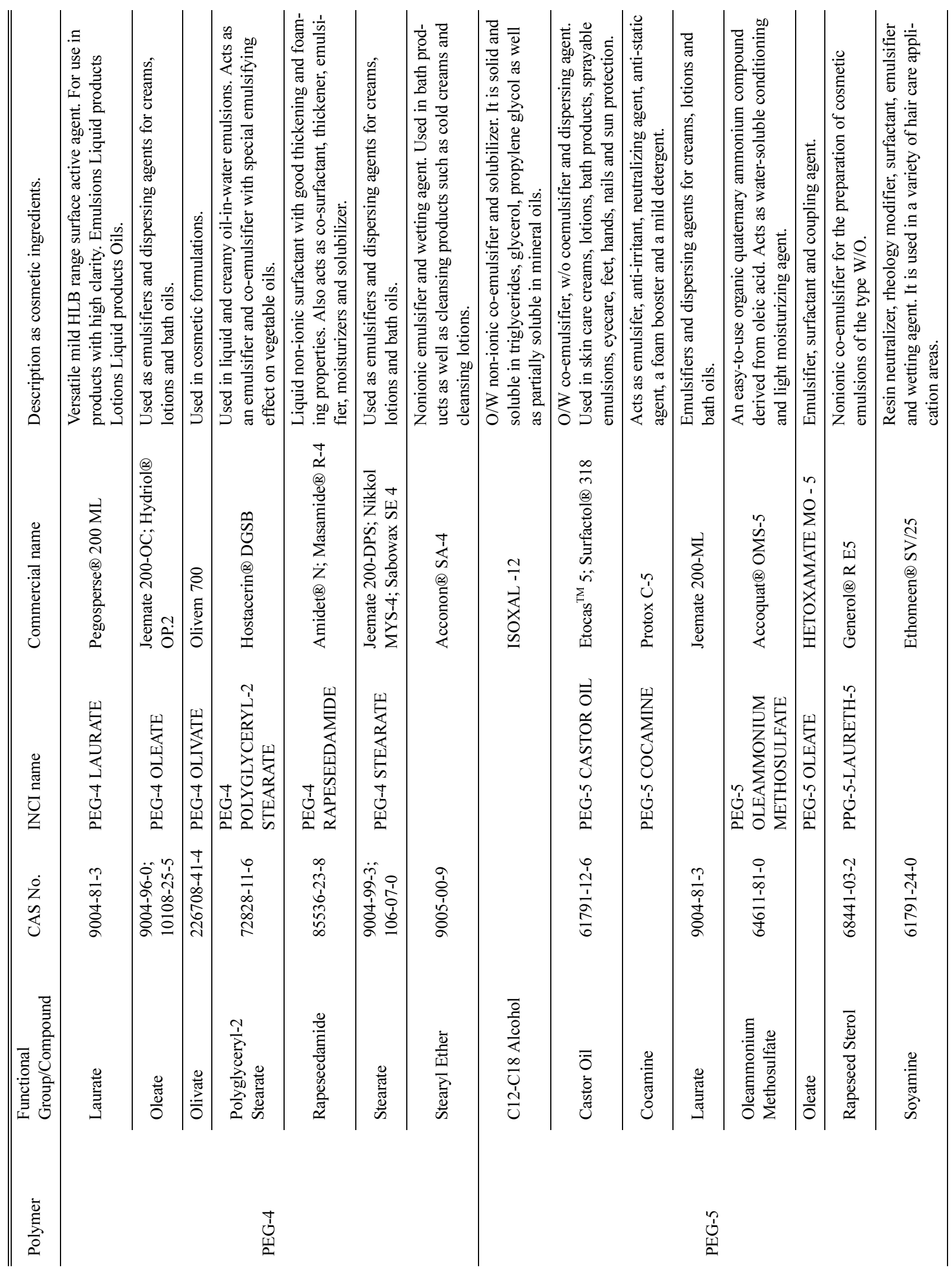




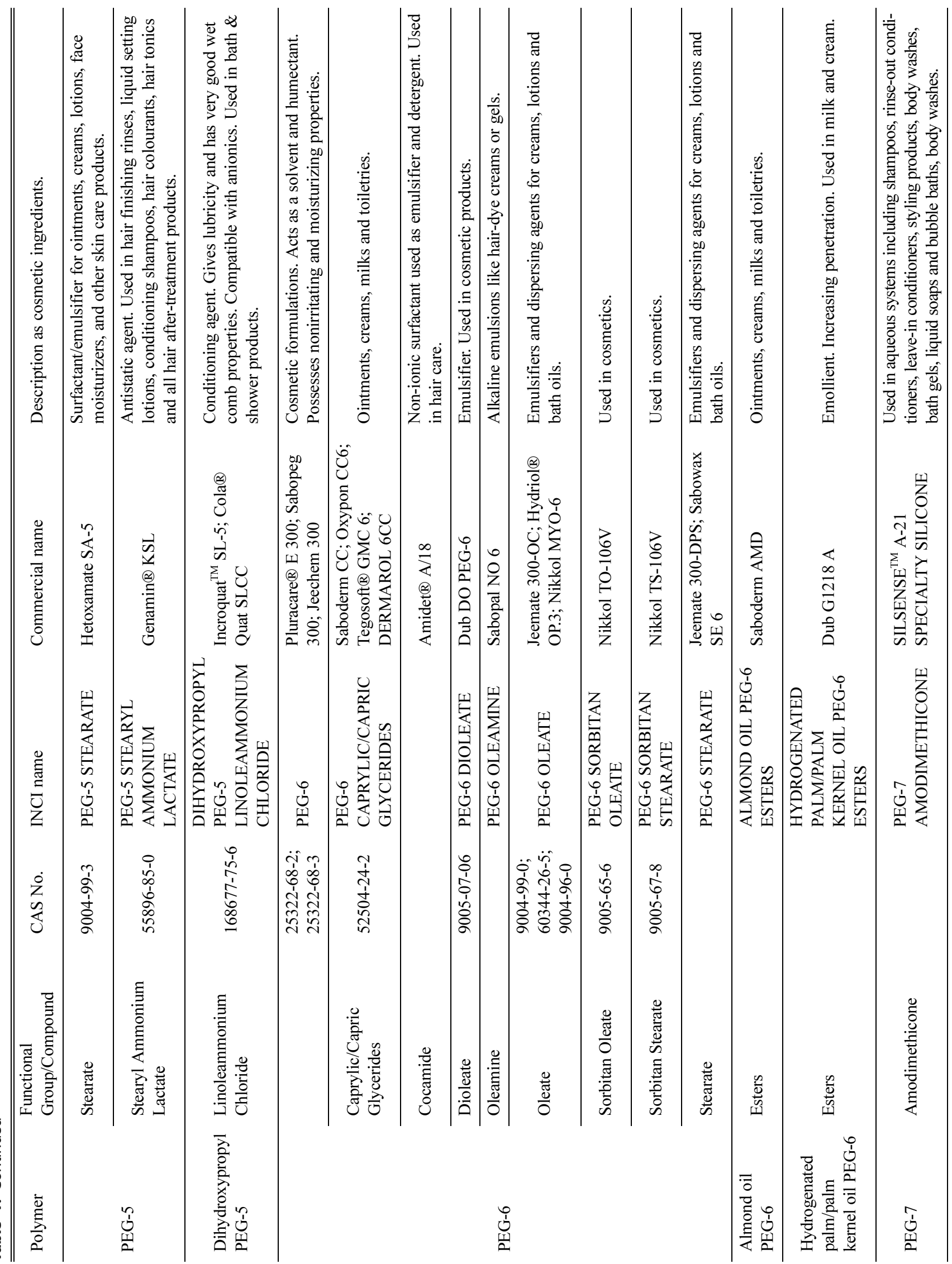




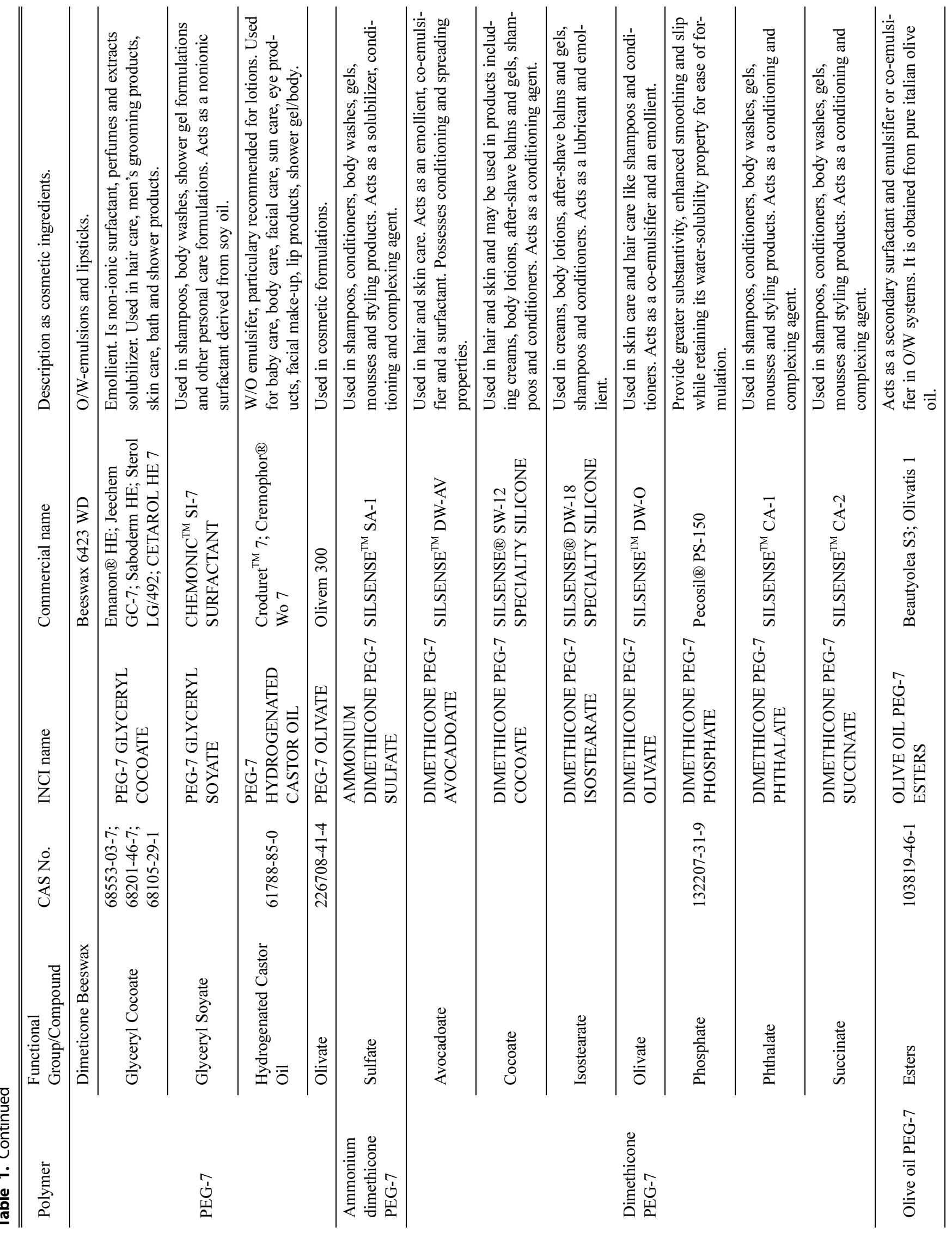




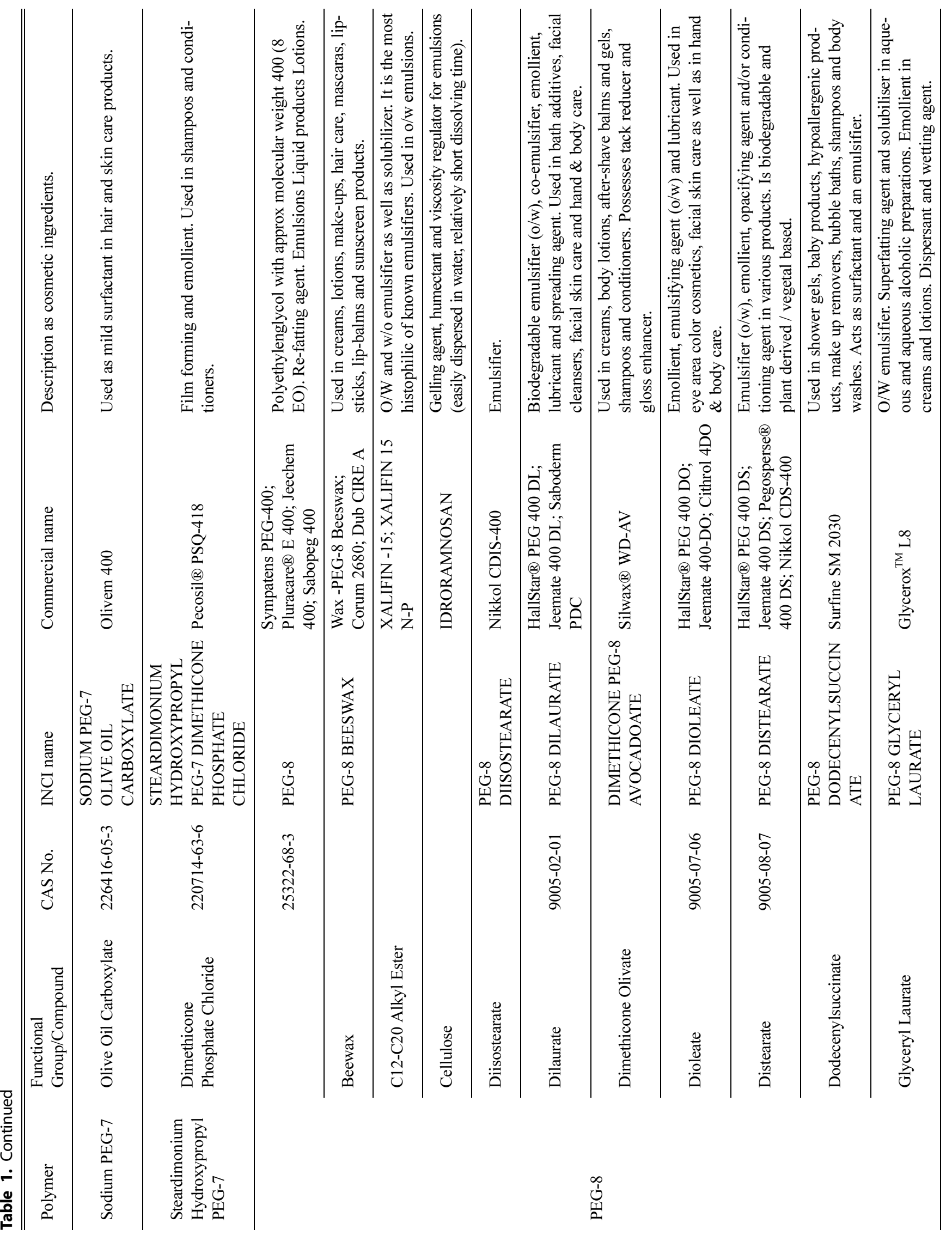




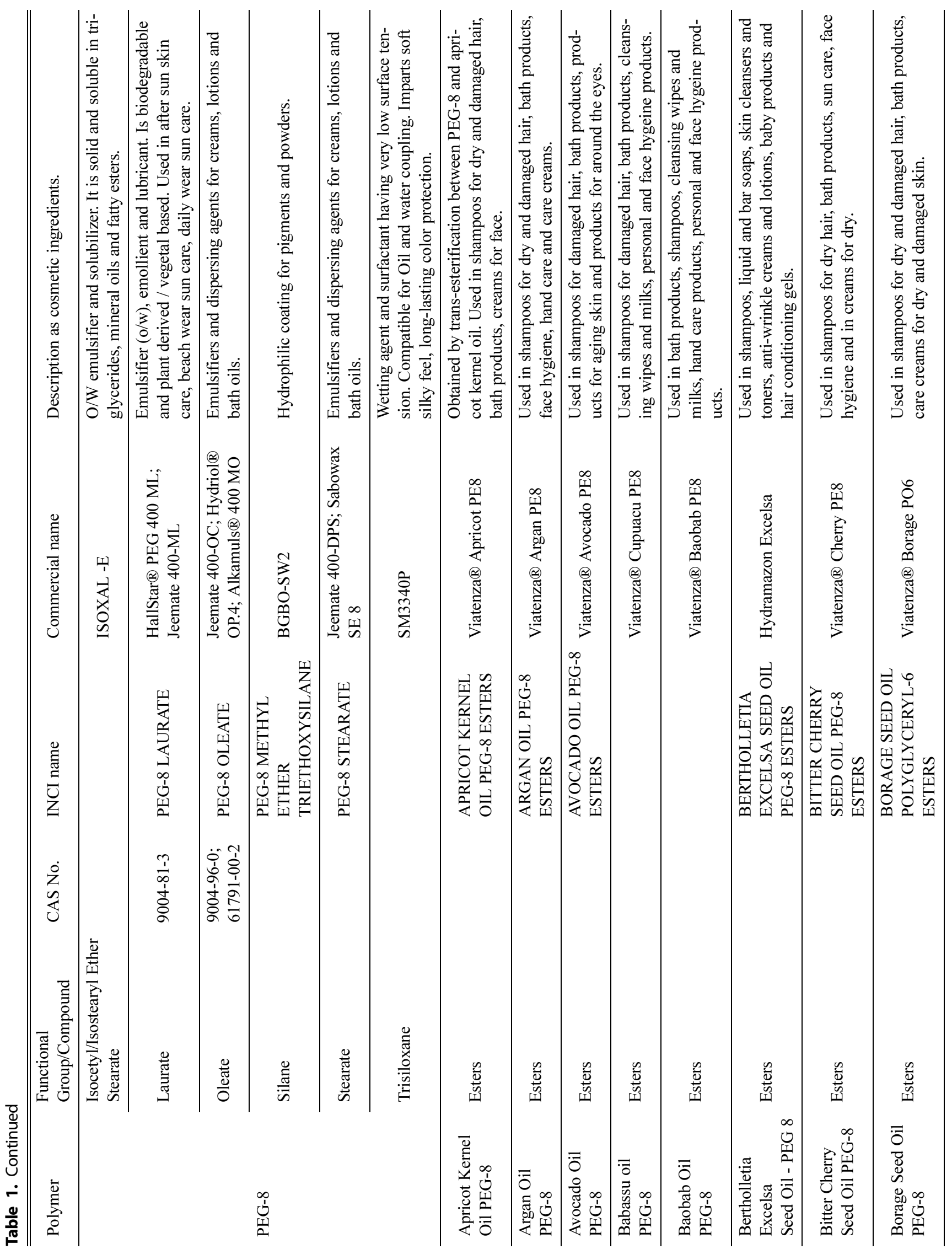




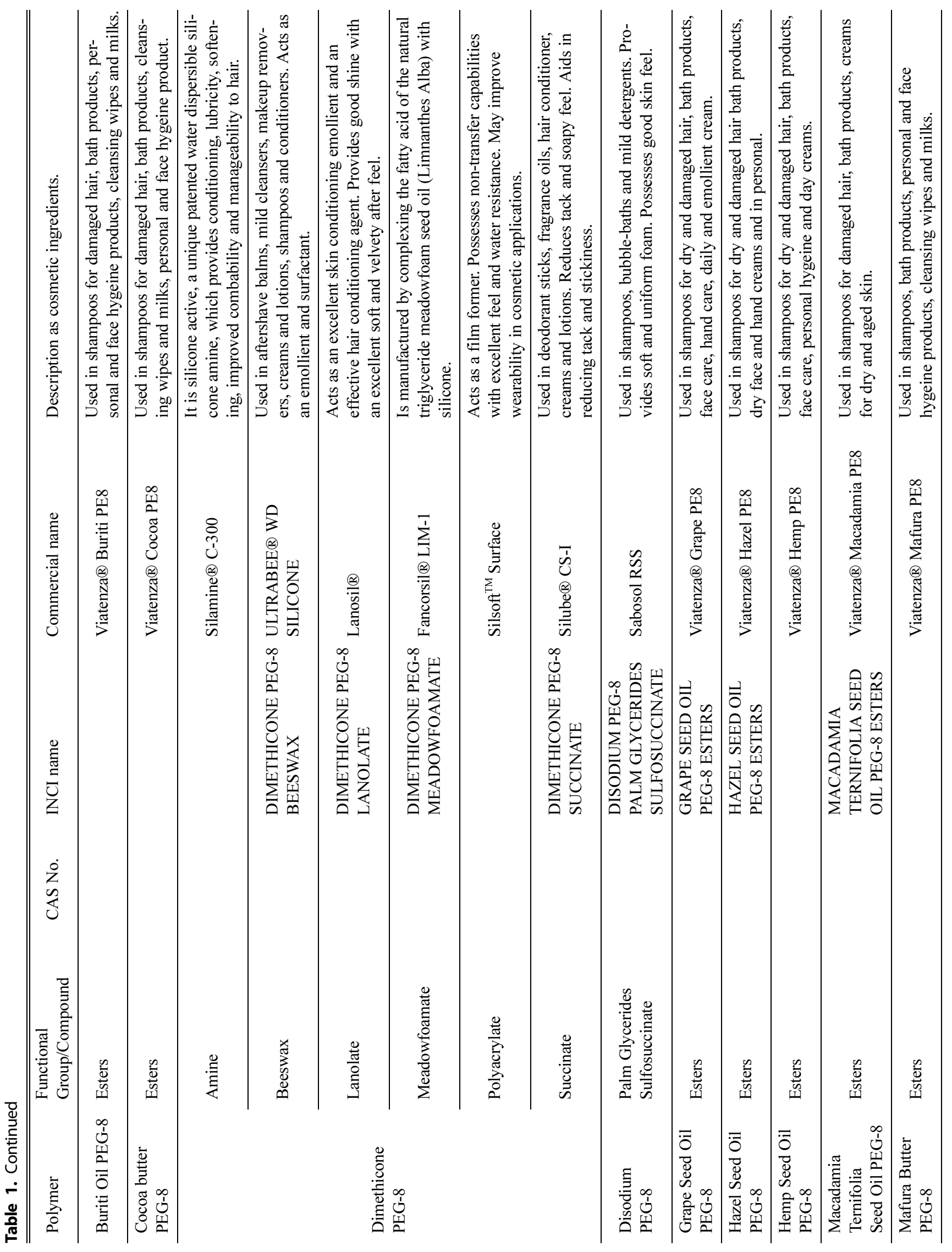




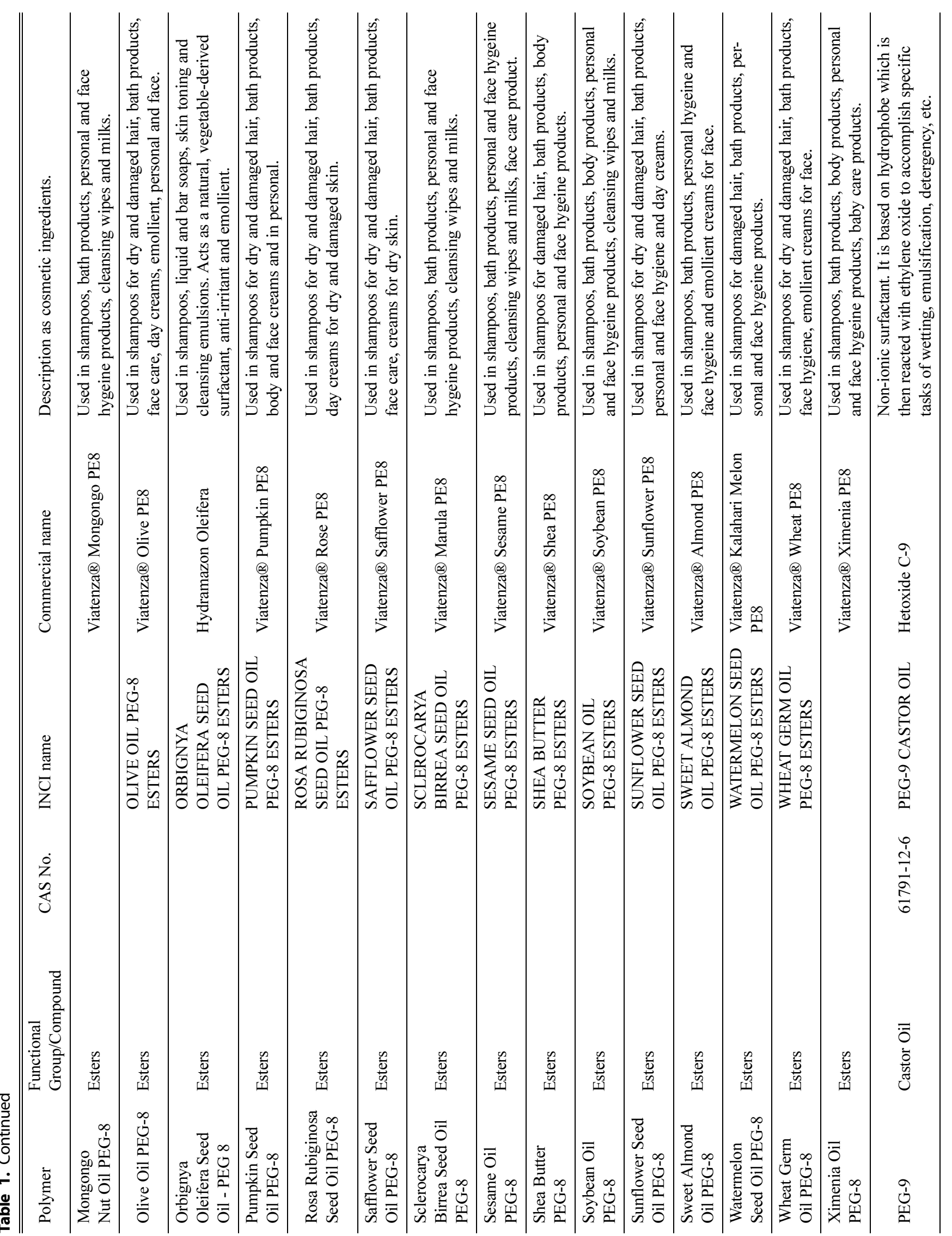




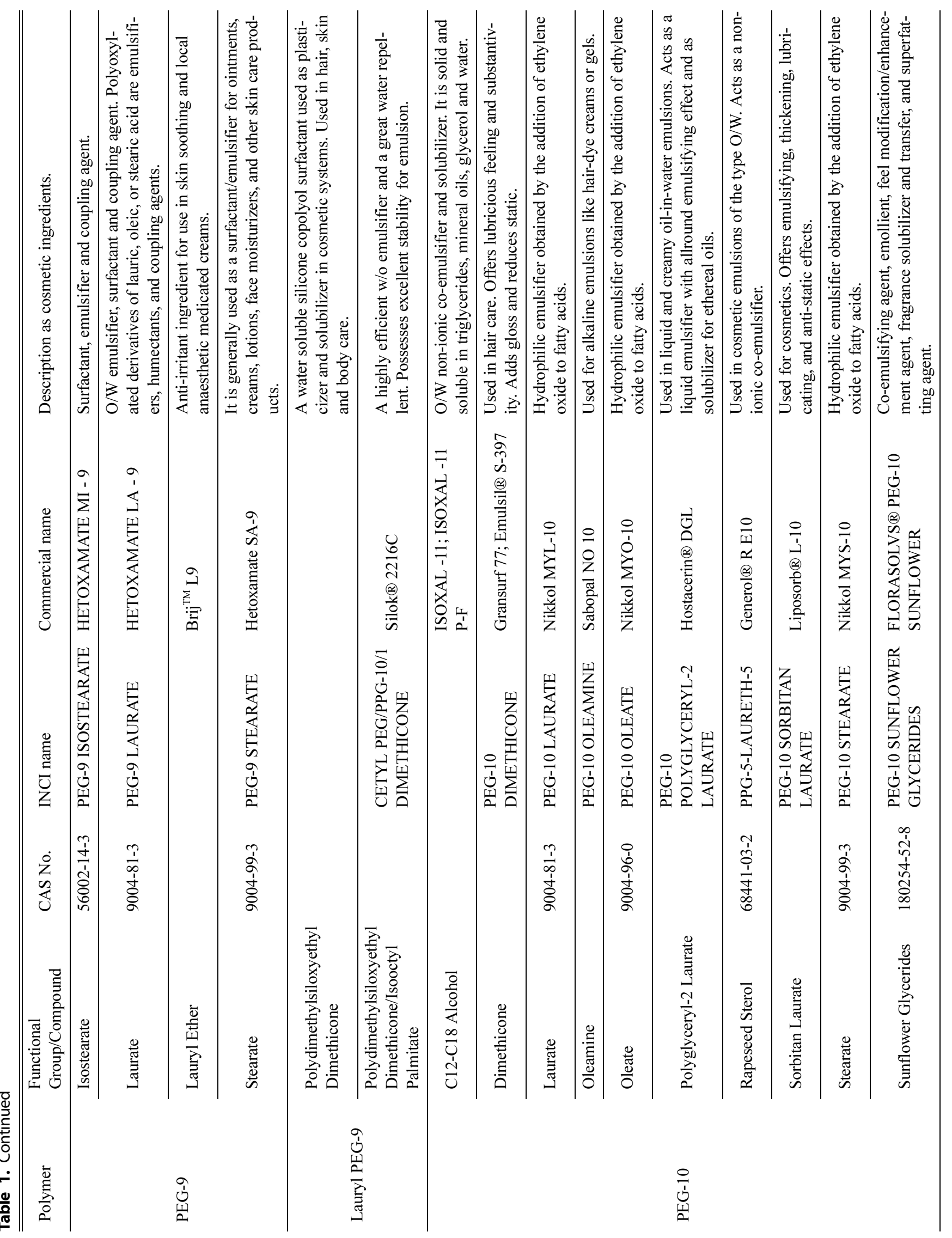




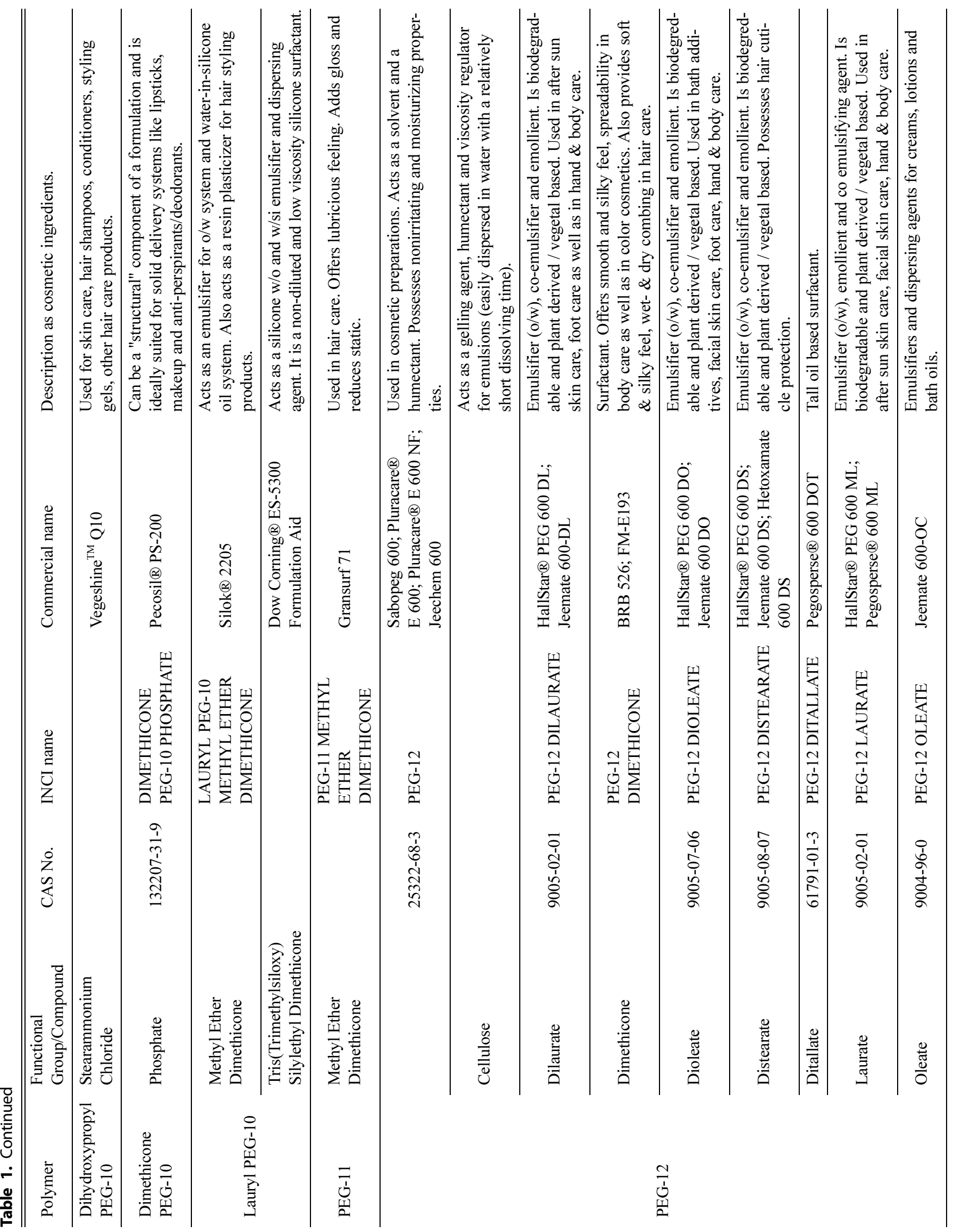




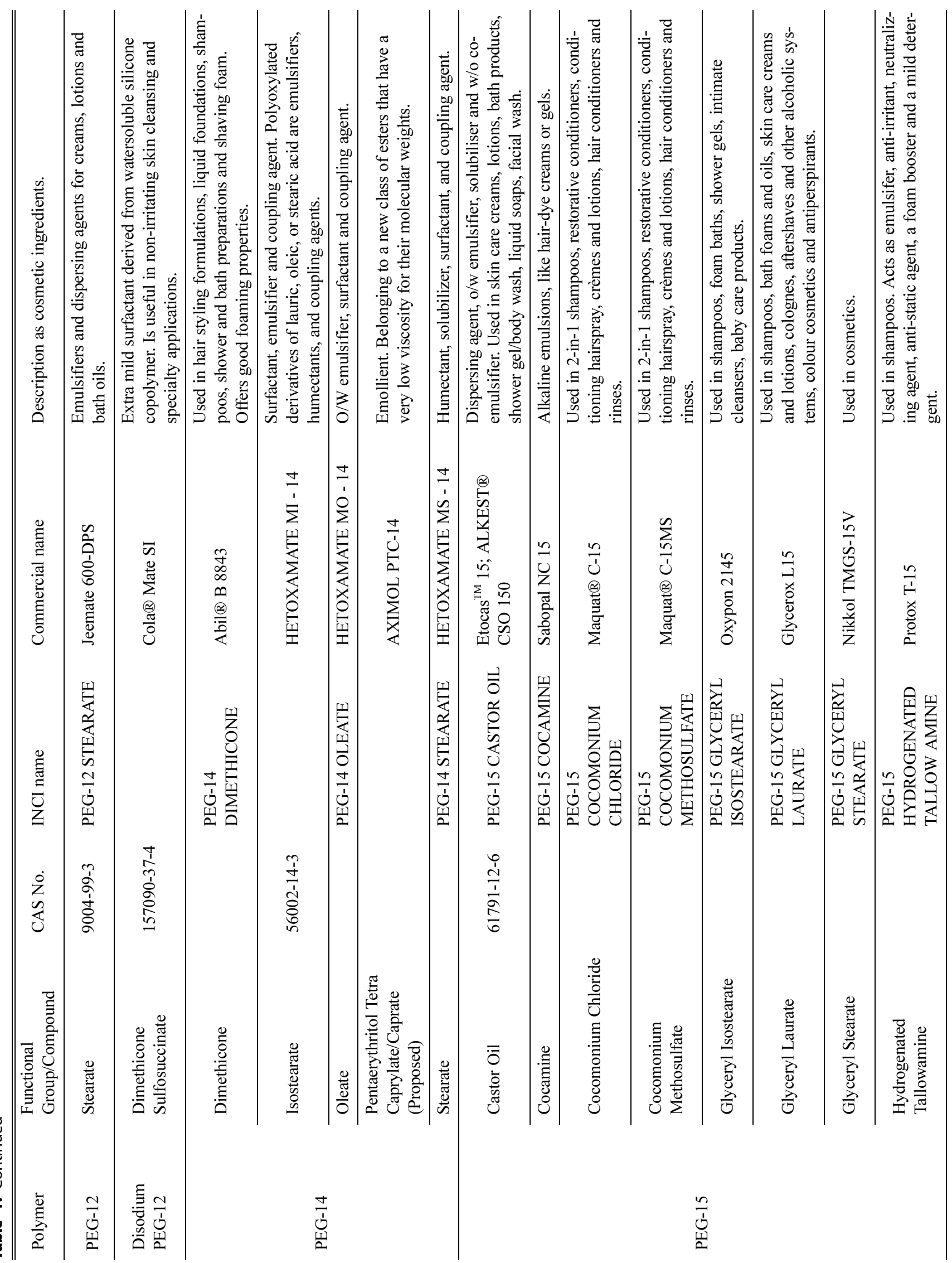




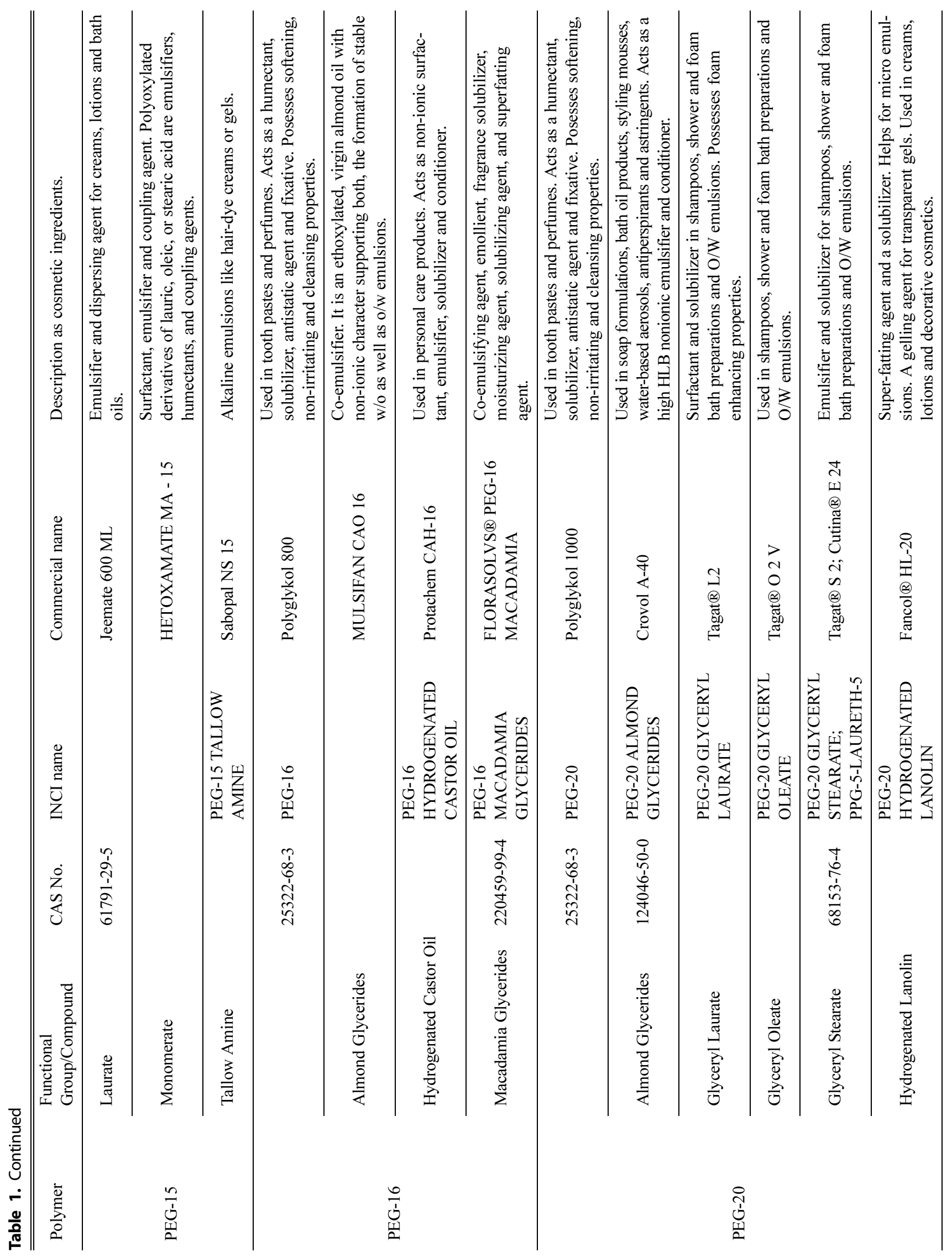




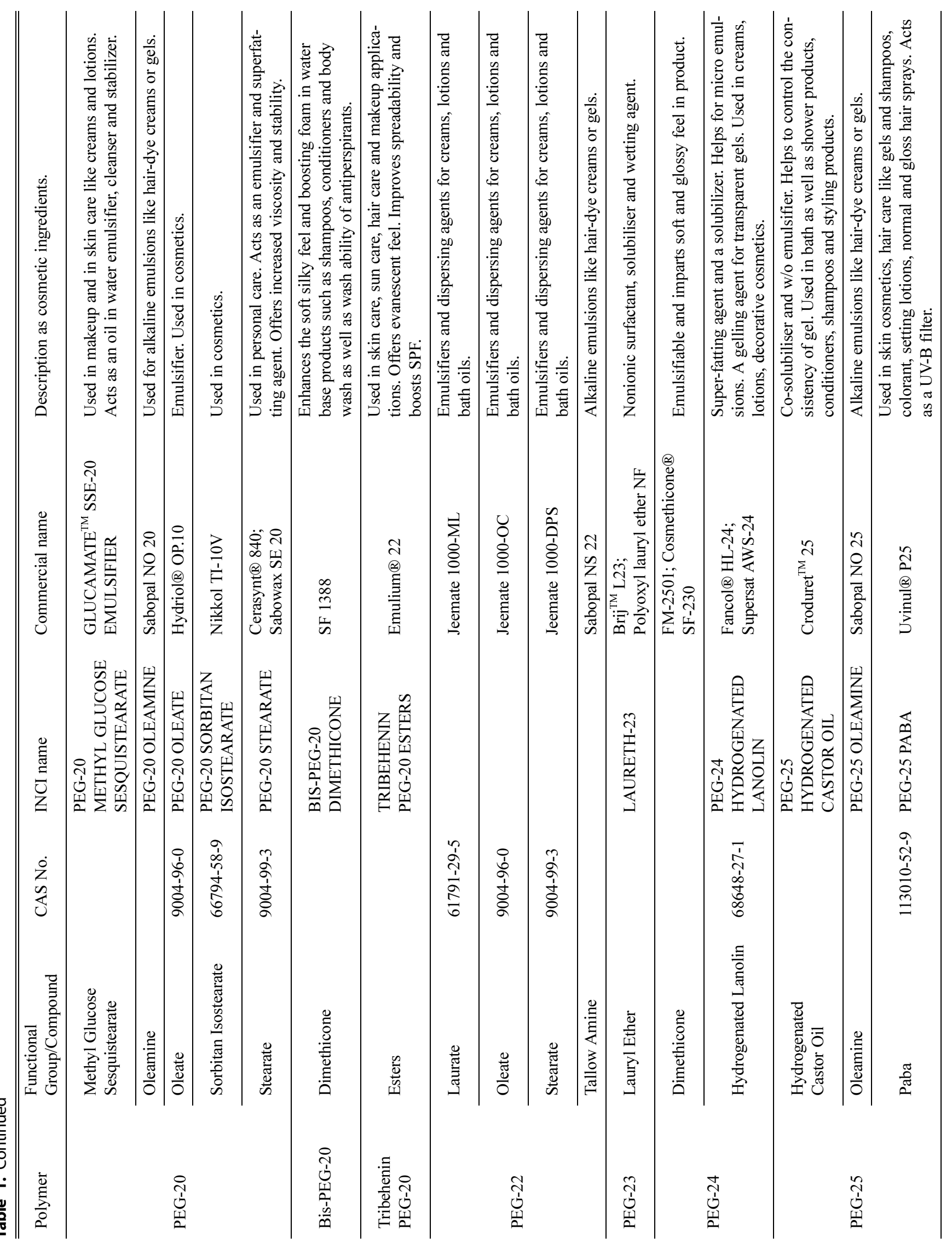




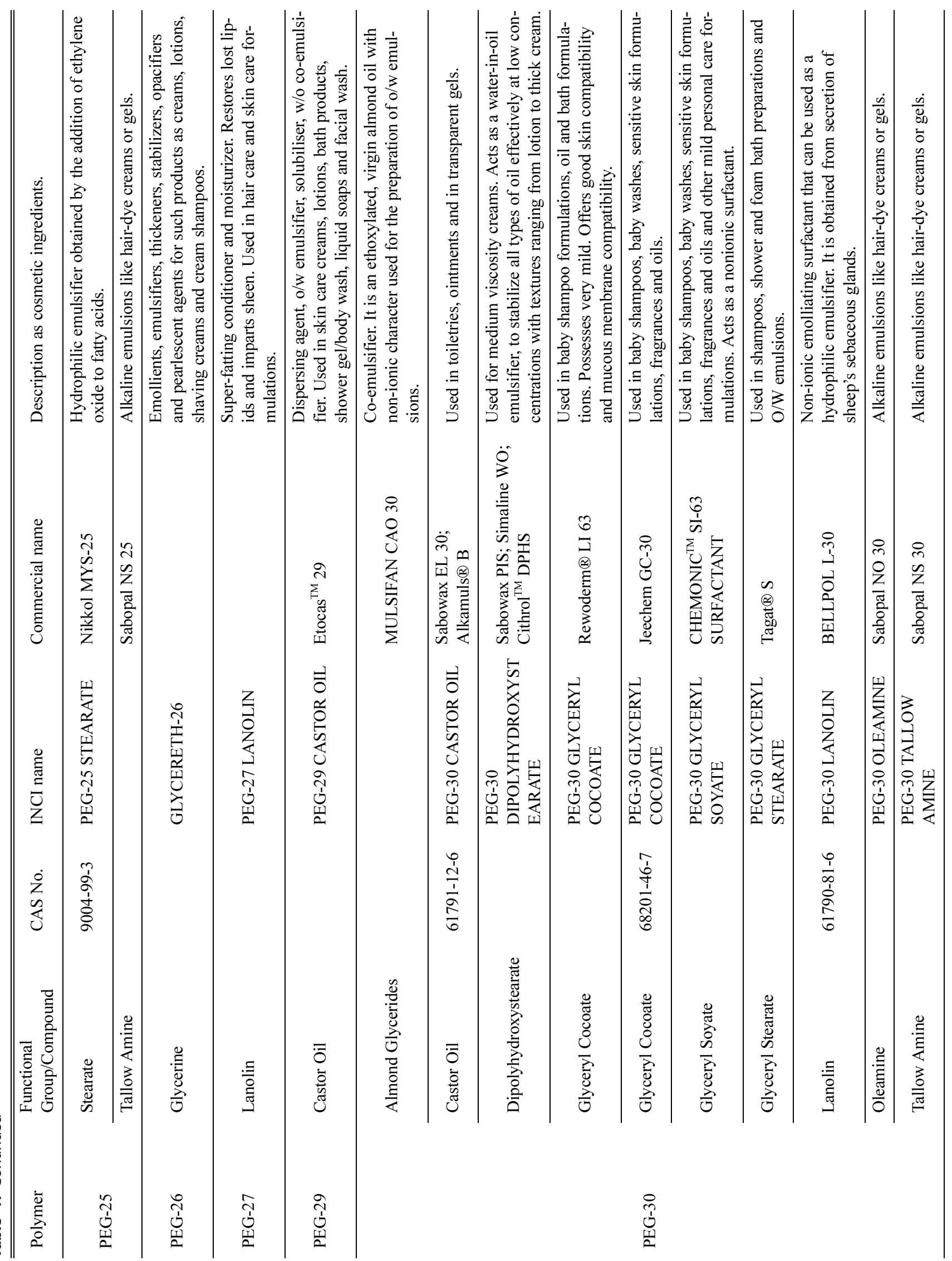




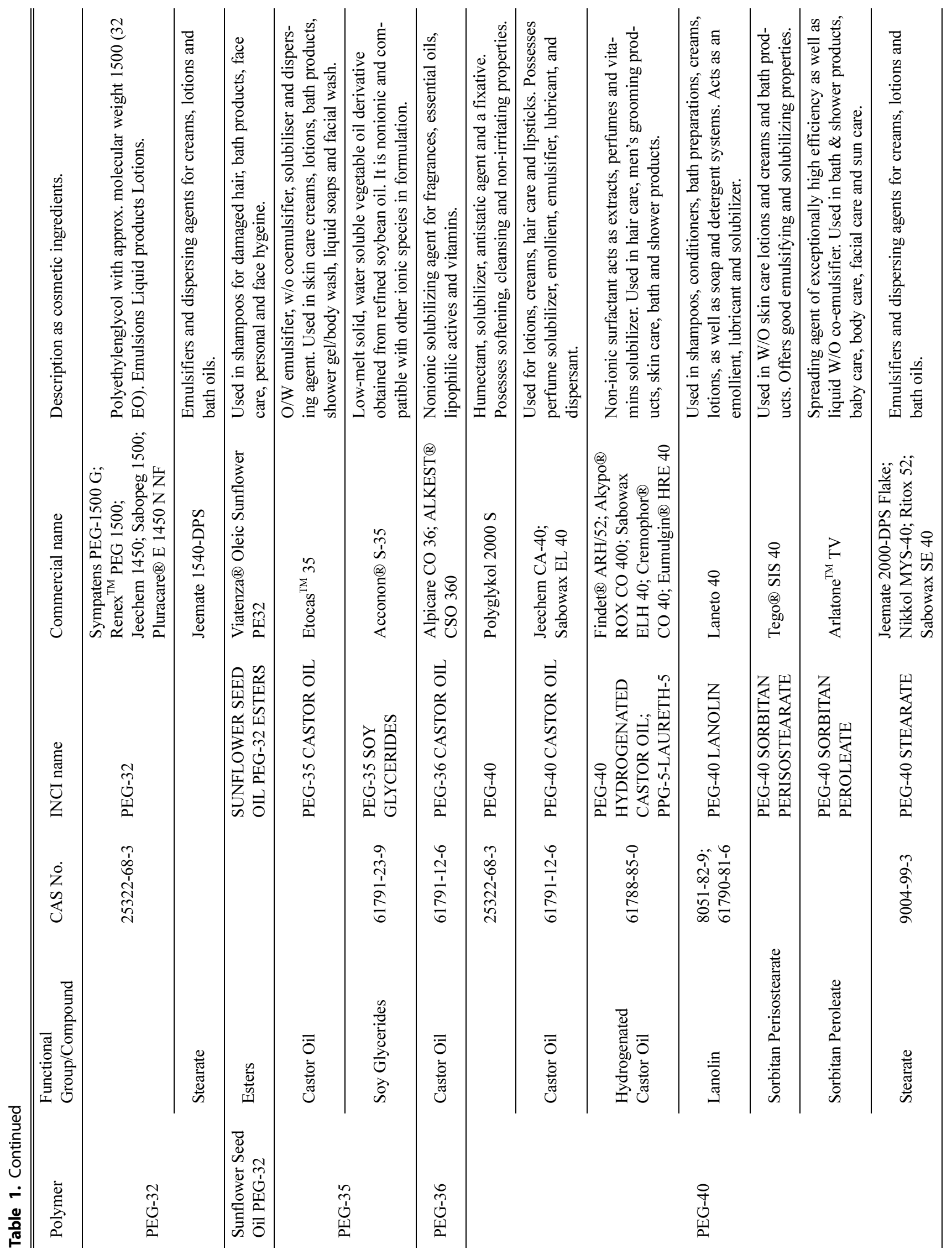




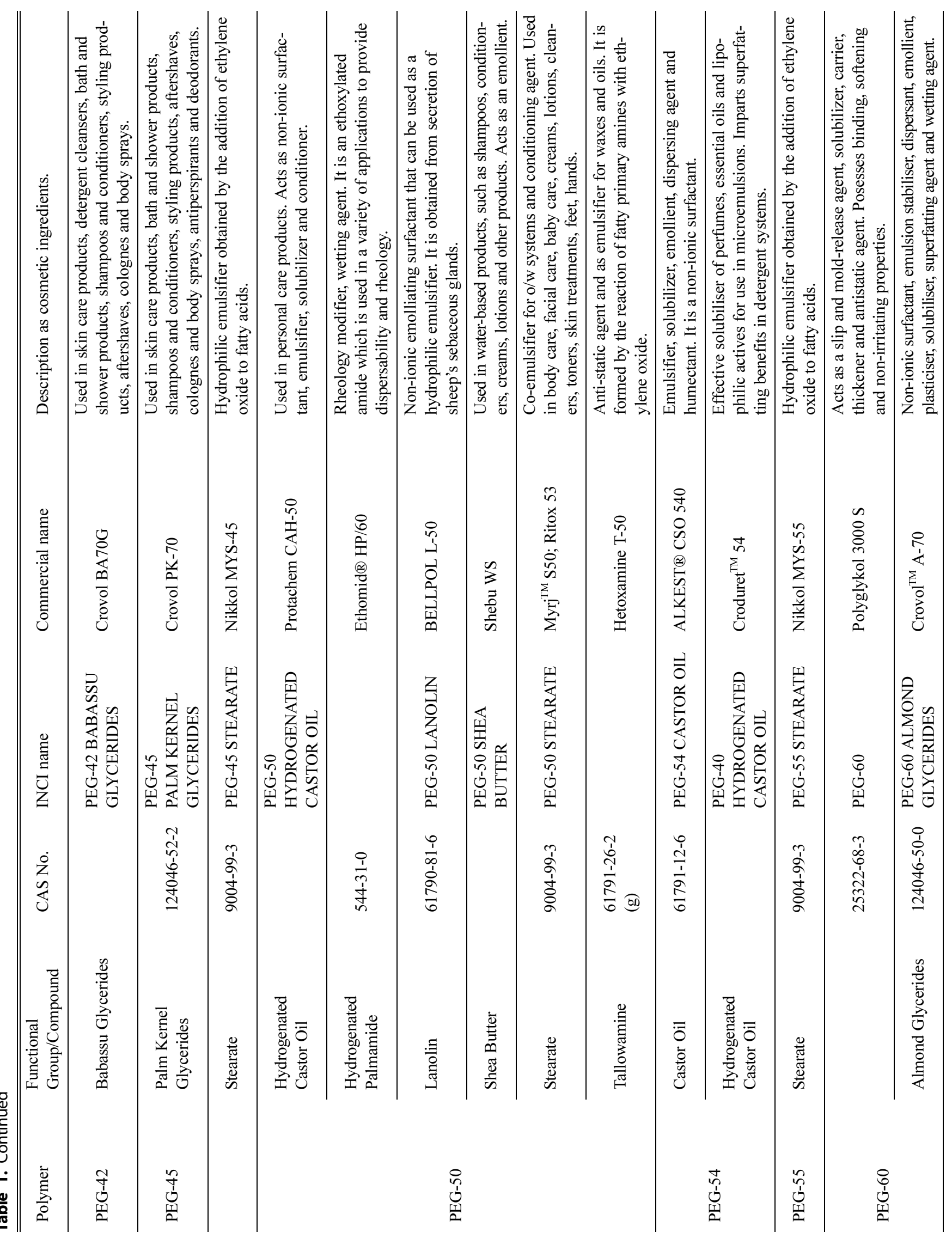




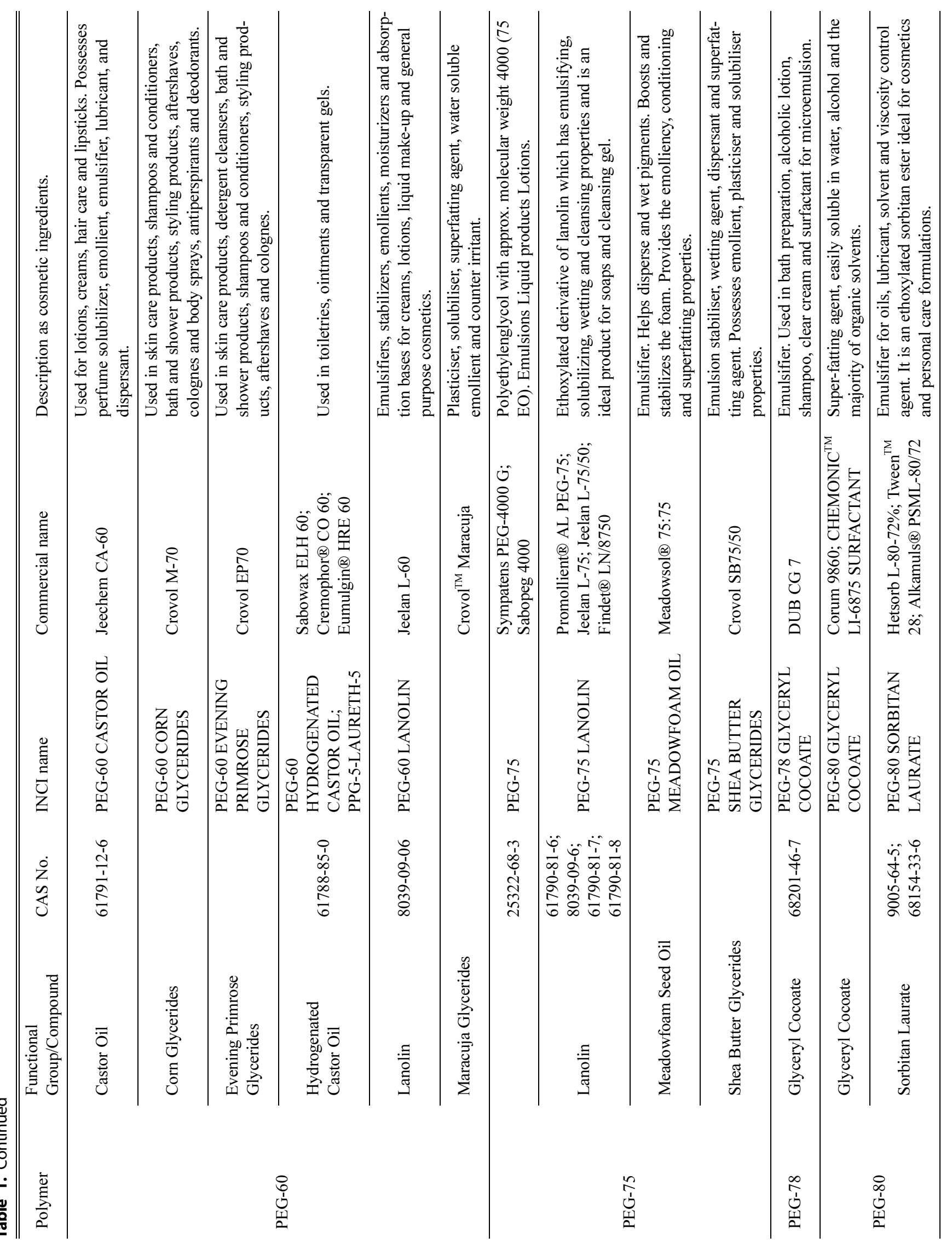




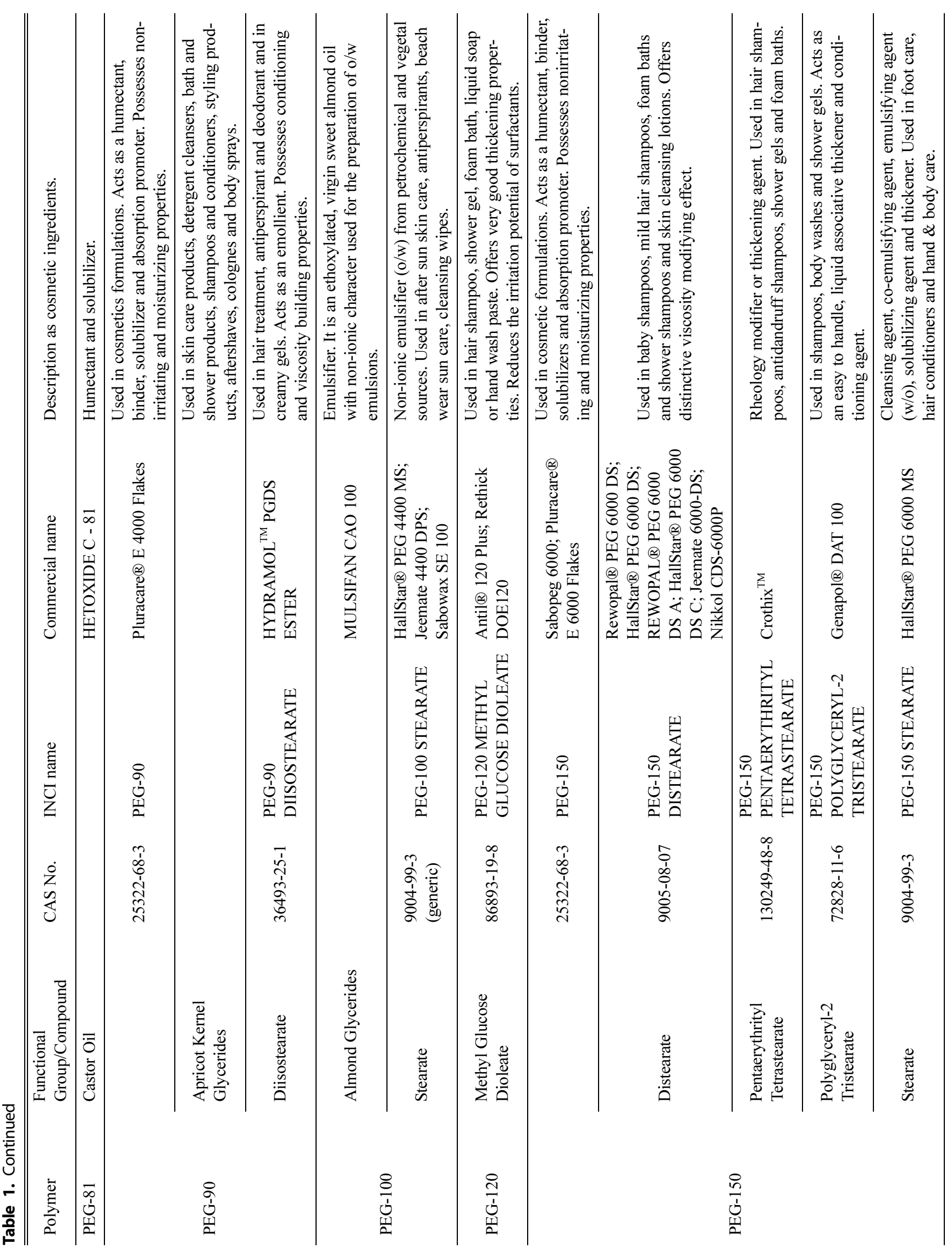




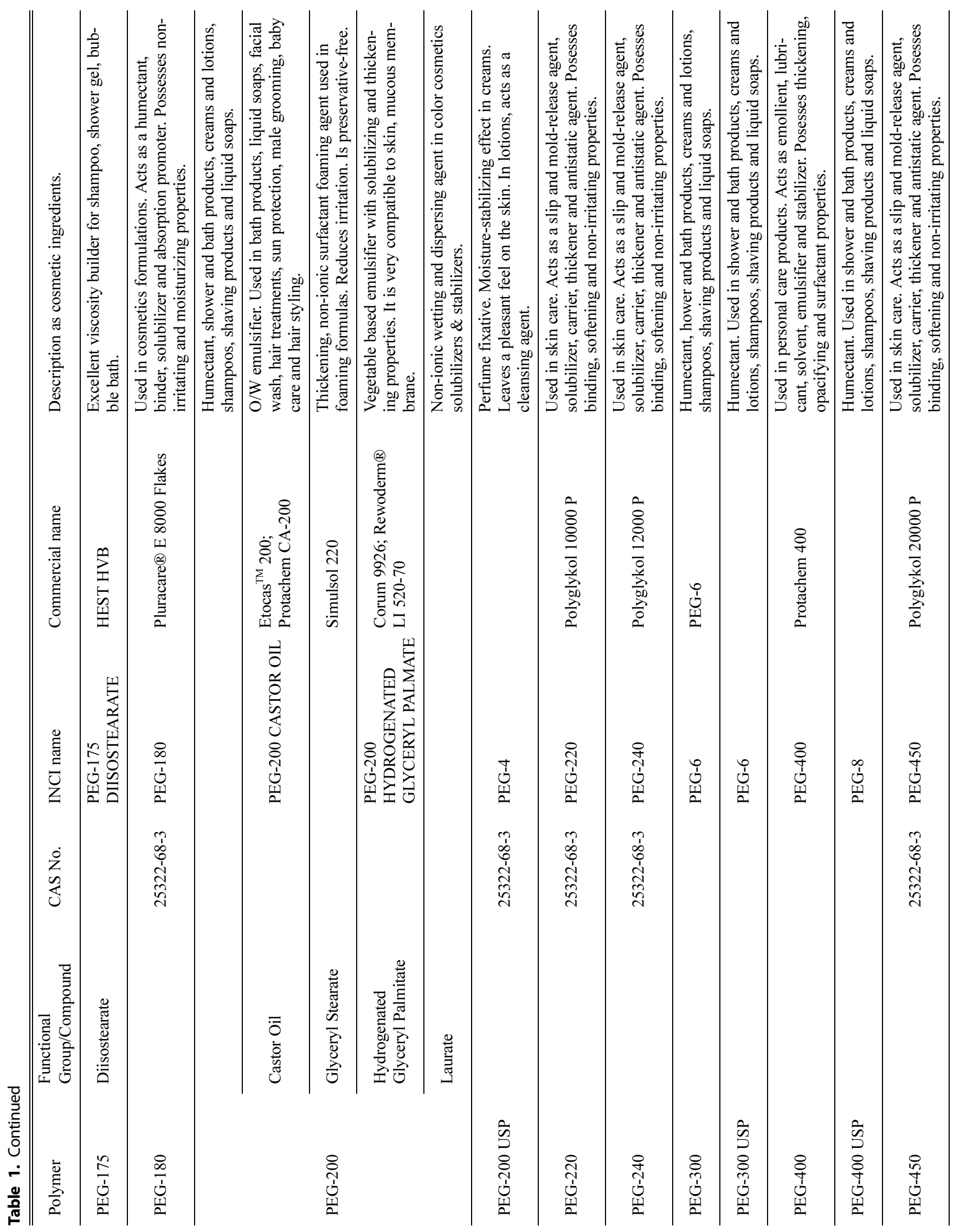




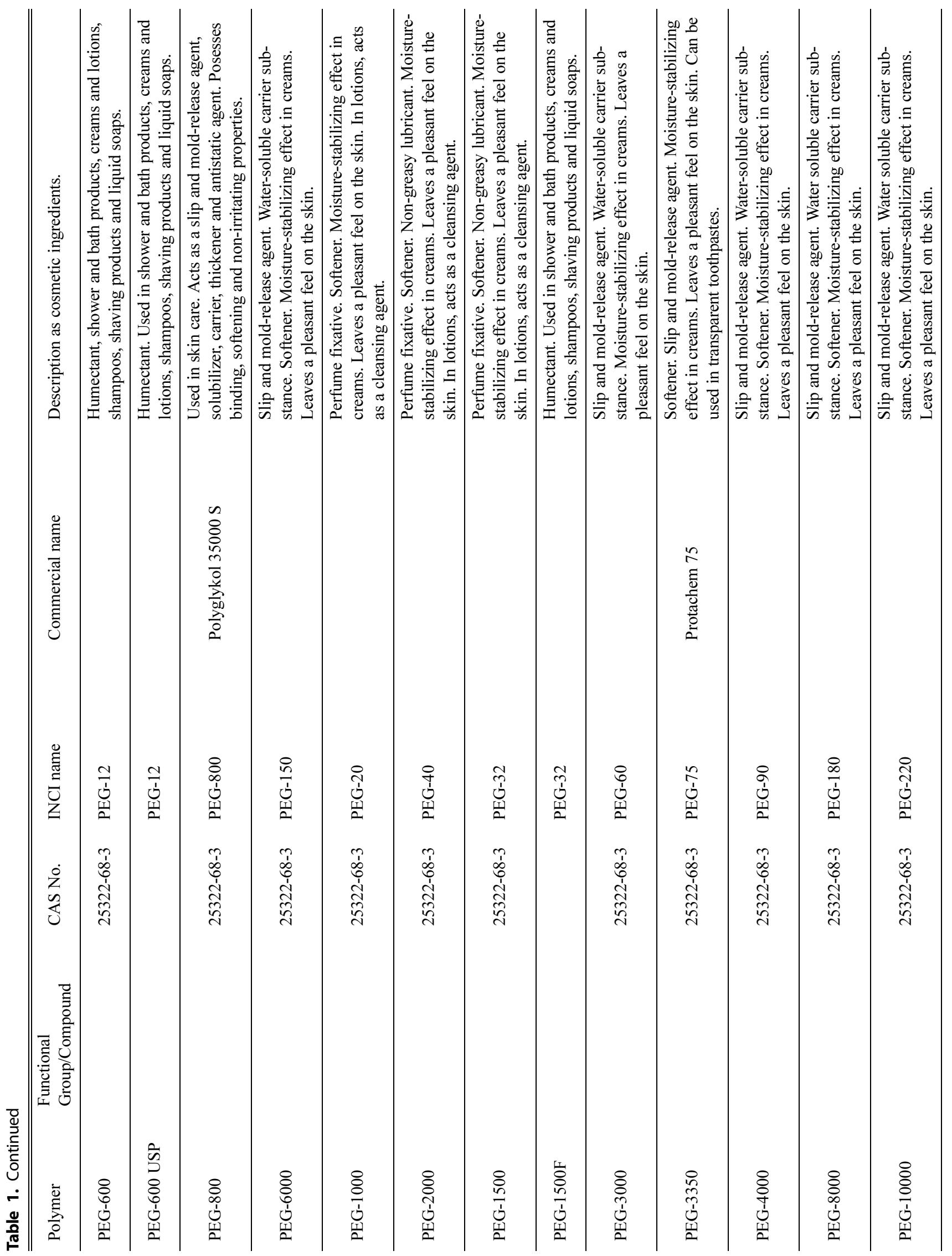




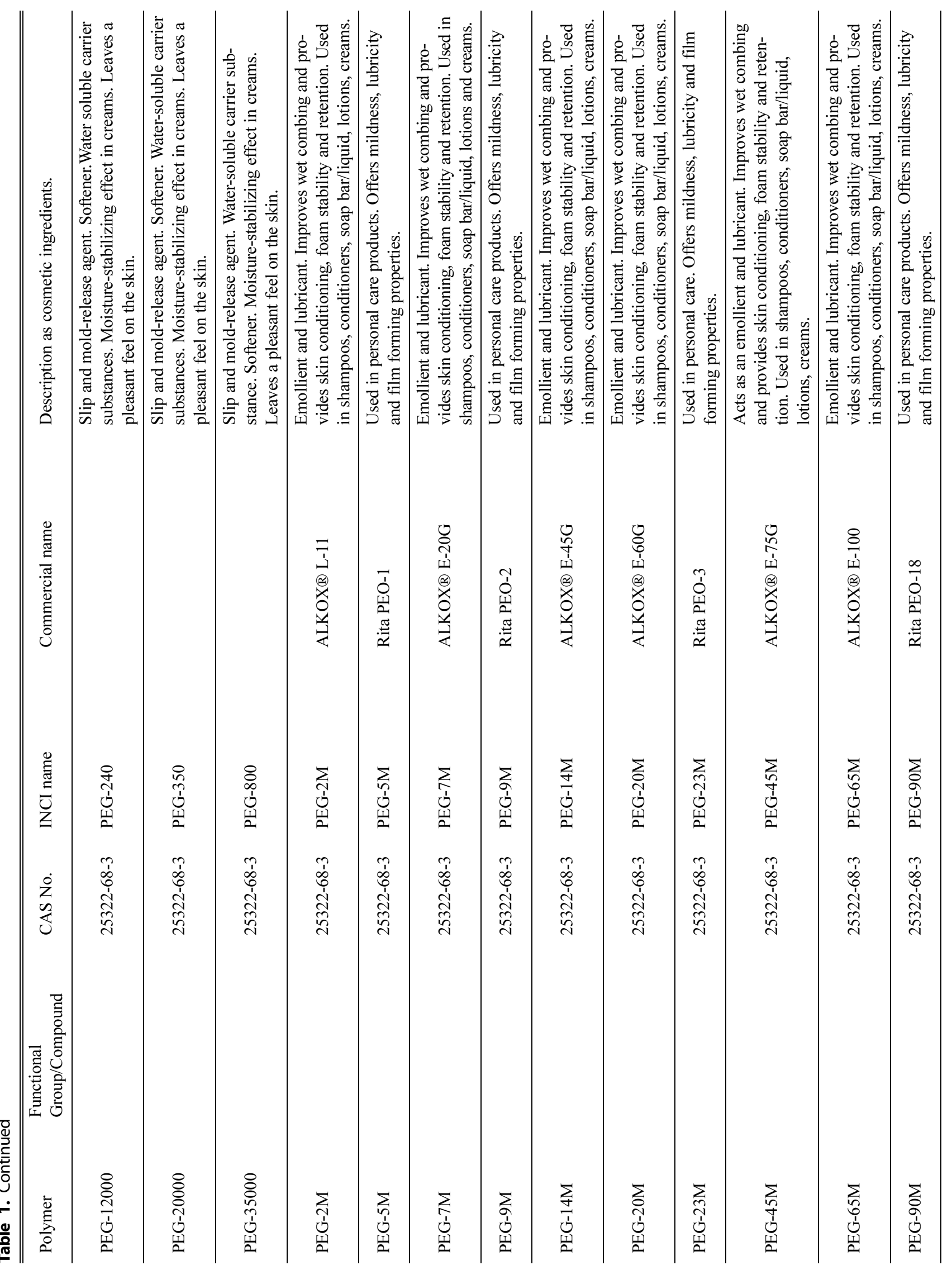




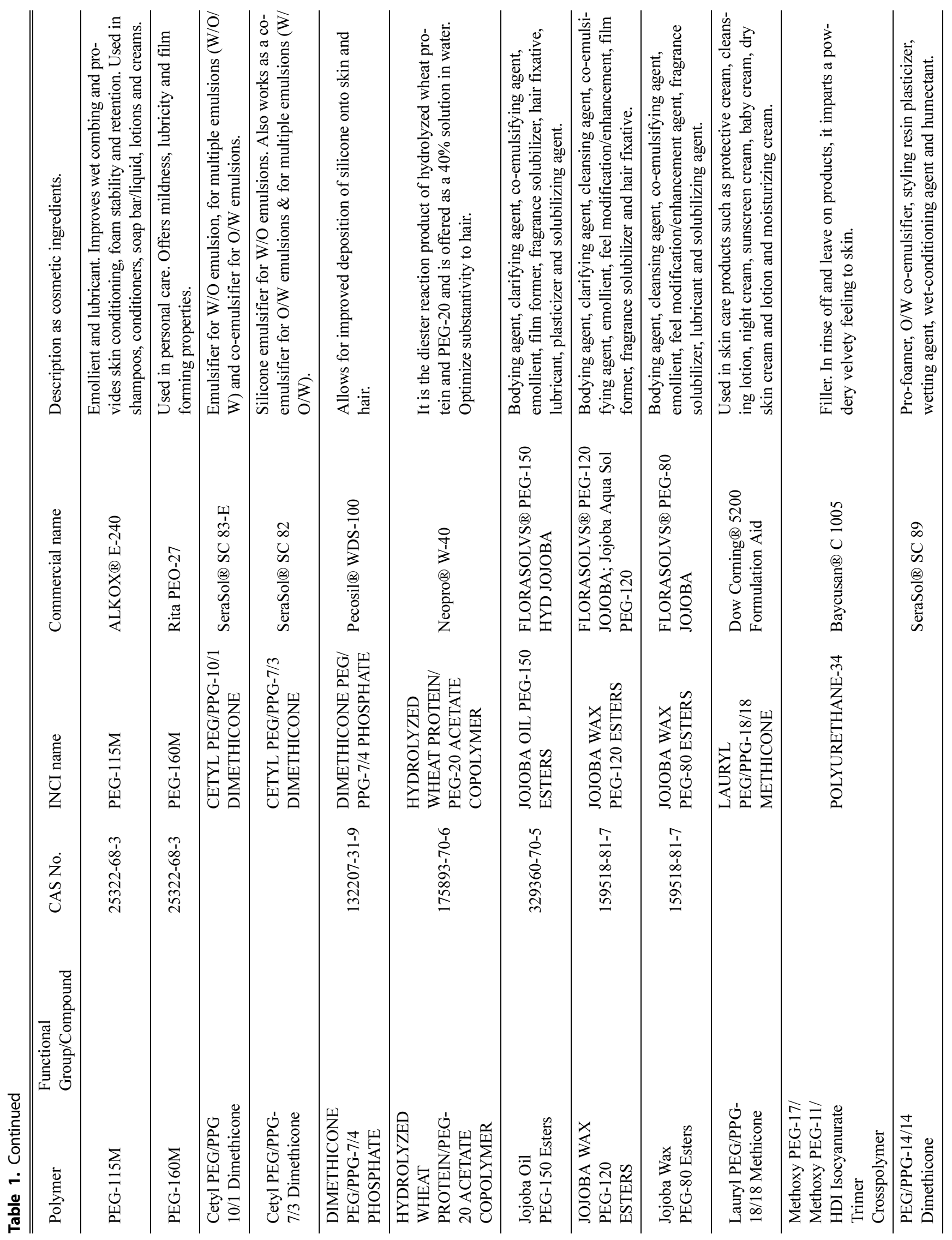




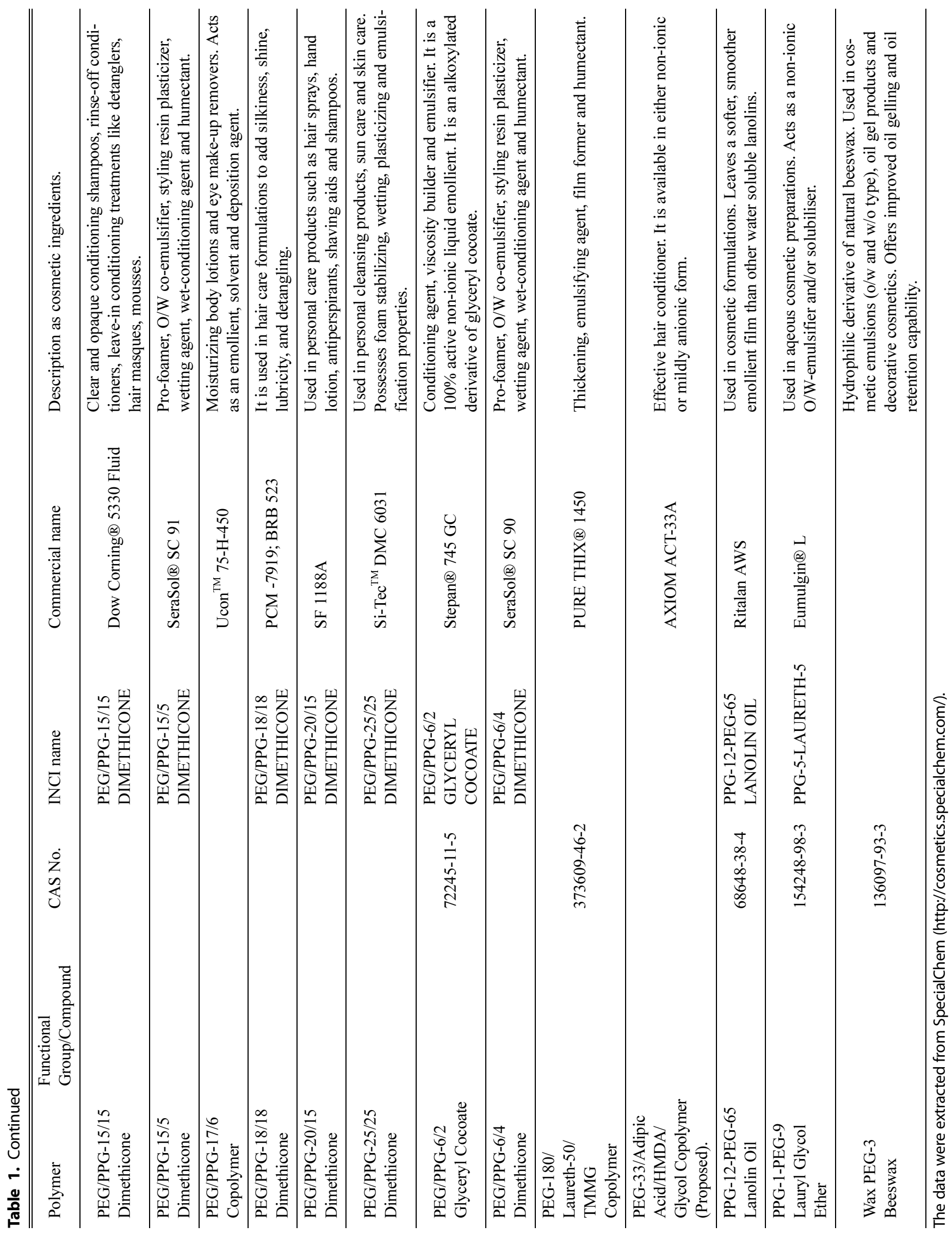


related to the general properties of its related mixtures, unless specific studies can be found. As much as we would like to know the specific effects of PEG/PPG-17/6 copolymer both in animal and human studies, we suggest that further evaluation should be needed if safety issues are found in its analogue mixtures. PEG/PPG-17/6 copolymer belongs to a group of copolymers of ethylene and propylene glycols with a variety of mixed names from a generic formula of "PPG-n-PEG-m", where $\mathrm{n}$ and $\mathrm{m}$ signify their average respective monomer units bound to each other randomly. Non-random or block copolymers have specifically assigned denominations with rules that include "poloxamer", "meroxapol" and "poloxamine" (9). Since very little is known about the specific properties of PEG/PPG-17/6 copolymer, the generic "poloxamer" will be described in this evaluation. Poloxamers follow a general formula, where $\mathrm{x}, \mathrm{y}, \mathrm{z}$ values depend on the mixture type (10). Poloxamers are water soluble and can form gels in a concentrated aqueous solution, which is reversible to liquid form after lowering the temperature, and vice versa. Viscosity of poloxamers depends on the increasing percentages of polyoxypropylene hydrophobe and polyoxyethylene hydrophile. As mentioned, PEG/PPG-17/6 copolymer could be under the umbrella of alkyl PEG-PPG ethers. This compound is produced from the reaction of an alkyl alcohol to any equivalents of both ethylene oxide and propylene oxide forming repeats in both PEG and PPG. Although these ethers are known to be surfactant-like molecules, having both hydrophobic and hydrophilic ends in their chain structures, they differ mainly in variations of their alkyl length, and the number of PEG and PPG repeat units in their hydrophobic ends. In each ingredient, the actual order of repeat units of alkoxides from different sources may be block, alternating, or random. PEG/ PPG-17/6 copolymer is known to be of the random type. Specific physical properties of the alkyl PEG-PPG ethers are mostly unidentified, with only a known physical form of clear to slightly yellowish liquids (8). Furthermore, each ingredient/compound group is expected to have different properties.

Only the production of poloxamers is known, where generally it is an ordered mixture of propylene oxide, propylene glycol, and ethylene oxide prepared at high temperature and pressure along with an alkaline catalyst (e.g. sodium or potassium hydroxide), which becomes neutralized to become part of the final product (11). PEG/PPG-17/6 copolymer has been identified as a solvent in cosmetic products (12) as well as an emollient and surfactant (13).

Since no toxicity studies can be found for PEG/PPG$17 / 6$ copolymer specifically, the general evaluations of its chemical analogue "poloxamers" are drawn. According to the Cosmetic Ingredient Review (CIR) expert panel, the presence of impurities during or after the process of mixing these compounds is of concern, including 1,4-dioxane, ethylene oxide, and propylene oxide, which are known to be carcinogenic and/or highly volatile. Thus, it was emphasized that purification of end mixtures before incorporation into cosmetic products should be carried out as a necessity in order to keep these impurities to very minimum levels of $1 \mathrm{ppm}$ for 1,4-dioxane and $5 \mathrm{ppm}$ for ethylene oxide and propylene oxide. In addition, toxicology studies for poloxamers suggested "a low order of toxicity" in all acute to chronic animal testing, including the negative results for genotoxicity and carcinogenicity studies. No reproductive or developmental toxicity studies have been conducted thus far. In both animal and human testing, poloxamers were not dermally irritating or sensitizing. Finally, poloxamers are concluded as safe for cosmetic use according to the current concentrations applied, and according to the manufacturers' ability to remove their impurities (8). Accordingly, PEG/PPG-17/6 copolymer may have the same properties and effects as long as impurities are kept acceptably low. However, a more specific assessment for this ingredient is highly recommended to draw indubitable conclusions for the safety of its use in cosmetics.

PEG-20 glyceryl triisostearate. PEG-20 glyceryl triisostearate is a nonionic compound with a molecular weight of more than 1,000, and is used as an emulsifier, dispersing agent, and solubilizing agent in cosmetics and personal care products. It is mainly used in both rinse-off cleansing products such as facial cleansers or body washes and leave-on products such as creams or lotions. The cleansing and leave-on products contain this chemical up to $20 \%$ and $5 \%$, respectively. PEG-20 glyceryl triisostearate is probably removed from the water up to $90 \%$ by partitioning to solids during water treatment processes. PEG-20 glyceryl triisostearate is not expected to bioaccumulate due to its high molecular weight and is not anticipated to cross biological membranes (14).

The exposure route of PEG-20 glyceryl triisostearate may be dermal, and the dermal exposure to the notified polymer is expected to be extensive due to daily application of PEG20 glyceryl triisostearate-containing cosmetic products. Thus, the exposure to PEG-20 glyceryl triisostearate for the public is expected to be widespread and frequent through the daily application of cosmetics (14). In spite of the widespread use of PEG-20 glyceryl triisostearate, the previous safety assessment of this chemical for humans was still not sufficient. Thus, this report provides the toxicological evaluation of PEG-20 glyceryl triisostearate as a cosmetic ingredient. The toxicological data of PEG-20 glyceryl triisostearate were estimated based on its chemical analogues including glyceryl triisostearate, sorbitan sesquiisostearate, and PEG-20 sorbitan fatty acid esters (Table 2) (15-17). Although these chemicals do not contain all of the functional groups present in PEG-20 glyceryl triisostearate, some properties of PEG-20 glyceryl triisostearate can be approximated using the component chemicals. Acute oral 
Table 2. Toxicological data of PEG compounds

\begin{tabular}{|c|c|c|c|c|}
\hline $\begin{array}{l}\text { Chemical } \\
\text { compound }\end{array}$ & Studies & Animal & Result & Ref. \\
\hline $\begin{array}{l}\text { Glyceryl } \\
\text { triisostearate }\end{array}$ & $\begin{array}{l}\text { Acute oral toxicity } \\
\text { Skin irritation } \\
\text { Skin sensitization } \\
\text { Eye irritation } \\
\text { Mutagenicity }\end{array}$ & $\begin{array}{l}\text { Rat } \\
\text { Rabbit } \\
\text { Guinea pig } \\
\text { Rabbit }\end{array}$ & $\begin{array}{l}\mathrm{LD}_{50}>2 \mathrm{~g} / \mathrm{kg} \text { bw } \\
\text { Non-irritant } \\
\text { Non-sensitizing } \\
\text { Non-irritant } \\
\text { Not mutagenic }\end{array}$ & (16) \\
\hline $\begin{array}{l}\text { Sorbitan } \\
\text { sesquiisostearate }\end{array}$ & $\begin{array}{l}\text { Acute oral toxicity } \\
\text { Skin irritation } \\
\text { Repeat insult patch test } \\
\text { Eye irritation } \\
\text { Mutagenicity }\end{array}$ & $\begin{array}{l}\text { Rat } \\
\text { Guinea pig } \\
\text { human } \\
\text { Rabbit }\end{array}$ & $\begin{array}{l}\mathrm{LD}_{50}>25 \mathrm{~g} / \mathrm{kg} \text { bw } \\
\text { Weak irritant } \\
\text { Non-sensitizing } \\
\text { Mild irritant } \\
\text { No data available }\end{array}$ & (17) \\
\hline $\begin{array}{l}\text { PEG-20 sorbitan } \\
\text { fatty acid esters }\end{array}$ & $\begin{array}{l}\text { Acute oral toxicity } \\
\text { Skin irritation } \\
\text { Repeat insult patch test } \\
\text { Eye irritation } \\
\text { Mutagenicity }\end{array}$ & $\begin{array}{l}\text { Rat } \\
\text { Rabbit } \\
\text { human } \\
\text { Rabbit }\end{array}$ & $\begin{array}{l}\mathrm{LD}_{50}>2 \mathrm{~g} / \mathrm{kg} \text { bw } \\
\text { Non-irritant } \\
\text { Non-sensitizing } \\
\text { Mild irritant } \\
\text { Not mutagenic }\end{array}$ & (15) \\
\hline $\begin{array}{l}\text { PEG-40 } \\
\text { Hydrogenated } \\
\text { Castor Oil }\end{array}$ & $\begin{array}{l}\text { Acute toxicity } \\
\text { Subchronic toxicity } \\
\text { Sensitization test } \\
\text { Dermal studies } \\
\text { Skin irritation } \\
\text { Reproductive and teratogenicity }\end{array}$ & $\begin{array}{l}\text { Rat } \\
\text { Rat } \\
\text { Human } \\
\text { Rat } \\
\text { Mouse, Rat } \\
\text { Rat }\end{array}$ & $\begin{array}{l}\mathrm{LD}_{50}>15.0 \mathrm{~g} / \mathrm{kg} \\
\text { No signs of abnormalities } \\
\text { Non-sensitizing effect } \\
\text { No microscopic changes } \\
\text { No signs of irritation } \\
\text { No significant maternal or fetal toxicity effects }\end{array}$ & $\begin{array}{l}(23) \\
(19) \\
(20,23,29) \\
(24) \\
(25,31) \\
(19)\end{array}$ \\
\hline $\begin{array}{l}\text { PEG-60 } \\
\text { Hydrogenated } \\
\text { Castor Oil }\end{array}$ & $\begin{array}{l}\text { Acute toxicity } \\
\text { Sensitization test } \\
\text { Ocular irritation } \\
\text { Dermal studies } \\
\text { Genotoxicity }\end{array}$ & $\begin{array}{l}\text { Rat } \\
\text { Human } \\
\text { Rabbit } \\
\text { Rat } \\
\text { Mouse }\end{array}$ & $\begin{array}{l}\mathrm{LD}_{50}>5 \mathrm{~g} / \mathrm{kg} \\
\text { No sign of irritation } \\
\text { Minimal irritation } \\
\text { The change within the normal range } \\
\text { No signs of toxicity }\end{array}$ & $\begin{array}{l}(26) \\
(27) \\
(28) \\
(29) \\
(30)\end{array}$ \\
\hline
\end{tabular}

toxicity of the PEG-20 glyceryl triisostearate is expected to have $\mathrm{LD}_{50}$ of more than $2,000 \mathrm{mg} / \mathrm{kg}$ bw. Furthermore, skin irritation and sensitization testing of PEG-20 glyceryl triisostearate is expected to be negative or weak. Indeed, there was no evidence of sensitization in the repeat insult patch test. Eye irritation and mutagenicity of this compound was not be observed. The main route of exposure to PEG-20 glyceryl triisostearate is expected to be dermal during application of cosmetics and personal care products. Interestingly, the high molecular weight and low water solubility of PEG-20 glyceryl triisostearate could inhibit its absorption through various routes including dermal, inhalation, and oral (14). Hence, based on the overall studies, PEG-20 glyceryl triisostearate would not be threatening nor toxic to consumers' health.

PEG-40 hydrogenated castor oil. PEG-40 hydrogenated castor oil, as the name implies, is a hydrogenated castor oil-derived PEG with an average of 40 moles ethylene oxide. It is mixed through the etherification and esterification of hydrogenated castor oil glyceride and fatty acid products, having forty equivalents of ethylene oxide (18). PEG-40 hydrogenated castor oil (trade name: Cremophor
$\mathrm{RH} 40$ ) is utilized as a non-ionic solubilizer and emulsifying agent. It had been used to solubilize many cosmetic products including ethereal oils, perfume compositions, vitamins, and hydrophobic active substances in aqueous and/or alcoholic solutions. The identified concentrations of PEG-40 hydrogenated castor oil in products are in the range of $0.00007 \%$ to $22 \%$, in which the maximum known concentration of $22 \%$ is contained in leave-on products (19).

There were few toxicological assessment data available for this specific compound. A patch test was conducted on 20 human volunteers using 100\% concentration of PEG-40 hydrogenated castor oil on the skin of the back area and observed after 24 and $48 \mathrm{hrs}$. No further details were stated, however no sign of irritation was concluded. Nevertheless, another single patch test using only $0.25 \%$ PEG- 40 hydrogenated castor oil as part of a formulation showed a mild reaction in 1 out of 20 human volunteers, which could be related to other ingredients in the formulation or an isolated hypersensitivity case (Table 2) (20).

A repeated insult patch test was conducted in 120 human volunteers with a formulation containing $0.05 \%$ PEG-40 hydrogenated castor oil. A volume of $0.10 \mathrm{~mL}$ of the formulation was applied for $24 \mathrm{hrs}$ on the back area of each 
subject through occlusive patching on Mondays, Wednesdays, and Fridays of the 3-week testing period. Challenge patching was carried out on previously untreated sites after a 2-week non-treatment period. Observations of the treated sites showed one incident of almost imperceptible erythema among 5 subjects during the induction phase of the study, while one of these subjects showed a mild reaction during 24 and $48 \mathrm{hrs}$ of the challenge patching. Another subject who did not show a reaction during the induction test also showed an almost imperceptible erythema during the challenge test. Follow-up testing of the 2 subjects who showed a reaction during the challenge test showed lesser reactions in which clinical significance could not be concluded. Thus, the overall findings of the study established a non-sensitizing effect of PEG-40 hydrogenated castor oil (Table 2) (29). A similar study using a higher concentration of PEG-40 hydrogenated castor oil at $0.25 \%$ in a formulation was tested in 86 subjects. During the induction testing, 2 subjects showed a mild reaction but not during challenge testing. One subject who did not show a reaction in the induction testing showed a faint erythema only at the $24 \mathrm{hr}$ grading period. Results could not conclude a sensitizing effect of the chemical at this concentration (Table 2) (23).

PEG-40 hydrogenated castor oil was also investigated for its sub-chronic treatment toxicity potential in animals. The first experiment was investigated in Sprague-Dawley (S-D) rats given an oral feed containing 0 (control), 10,000, 32,000 , and $64,000 \mathrm{ppm}$ of PEG-40 hydrogenated castor oil (20 males and 20 females in each group except 10,000, which had 25 animals of each gender). All animals survived during the experiment period and no significant feeding, body weight, or hematological changes were observed in any group. Necropsy further revealed no signs of abnormalities in the internal body components. In another study, a 6-month feeding period for PEG-40 hydrogenated castor oil was conducted in 3 male and 3 female beagle dogs using 0 (control), $1.0 \%, 2.5 \%$, and $5.0 \%$ concentrations. Observations during the study showed no significant changes in behavior, feeding, or body weight. Hematological and other biochemical parameters were of the same levels as the control group. One low-dose-treated animal died for reasons unrelated to the treatment. Necropsy further supported no evidence of toxicity in the feeding study (Table 2) (19).

Dermal studies for PEG-40 hydrogenated castor oil, contained at a concentration of $0.25 \%$ in a formulation, were conducted in 10 male and 10 female S-D rats through daily applications, 5 days a week for 13 consecutive weeks. The formulation was given at $1,640 \mathrm{mg} / \mathrm{kg} / \mathrm{day}$, which was believed to be 100 times greater than the average daily use by human consumers. During the entire duration of the study, all rats survived and no abnormal changes in behavior, body weight, hematology, urinalysis or chemical chemistry parameters were reported. In contrast, mild skin irritation at the treated site was observed starting on day 5 until the end of the study, as well as a significant elevation in hepatic weights in male rats when compared with the controls. Nevertheless, the finding was not considered relevant for toxicology since no microscopic changes were observed (Table 2) (24).

Skin irritation studies for PEG-40 hydrogenated castor oil contained at a concentration of $20 \%$ in a micro-emulsion were conducted in mice. The application site was the left ear that was given a single dose of $10 \mu \mathrm{L}$ of the material, while the right ear served as a control. During the 6 days observation, no signs of irritation could be seen in the treated ear with a $20 \%$ concentration of PEG- 40 hydrogenated castor oil (Table 2) (25). Another dermal irritation test using $20.66 \%$ PEG-40 hydrogenated castor oil, contained in a micro-emulsion gel, was conducted in male albino rats using the Draize method. Treated groups were given $0.5 \mathrm{~g}$ of the formulation, for 3 consecutive days, in a $5 \mathrm{~cm}^{2}$ dorsal side shaved skin area. A negative (no treatment) and a positive $(0.8 \%$ aq. formalin) control group was present. During the 3 days of observation, no signs of skin irritation could be seen for the test material, and the histopathological exam yielded negative skin irritation results (Table 2) (31).

Feeding studies for the assessment of reproductive and teratogenic effects of PEG-40 hydrogenated castor oil were conducted in pregnant S-D rats. One group (30 rats) was given 50,000 ppm and another 27 rats were given 100,000ppm PEG-40 hydrogenated castor oil from gestational day 0 to gestational day 20, while another 2 groups of untreated control were raised. Pregnant animals were monitored and assessed for signs of toxicity during gestation, and were sacrificed at gestational day 20 for fetal examination. Examinations of the mother and fetuses did not reveal any signs of toxicity. Although resorption and malformations/ anomalies were found in some animals in the highest dose group, similar changes were also found in the control group, showing no significant differences. Thus, the researchers conducting the study could not conclude teratogenicity for PEG-40 hydrogenated castor oil. Studies were also conducted in 4 groups of pregnant NMRI mice using 5,000 ppm (25 mice) and 10,000 ppm (31 mice) PEG-40 hydrogenated castor oil from day 6 to 15 of gestation; the other 2 groups were raised as controls. During the study, no significant maternal or fetal toxicity effects were found, and some malformations in fetuses in the treated groups were also comparable to the control groups (Table 2) (19).

PEG-60 hydrogenated castor oil. PEG-60 hydrogenated castor oil is a hydrogenated castor oil-derived polyethylene glycol with an average of 60 moles ethylene oxide. It is mixed through the etherification and esterification of hydrogenated castor oil glyceride and fatty acid products, having sixty equivalents of ethylene oxide. PEG-60 hydrogenated castor oils had 349 reported uses (with a similar 
function to PEG-40 hydrogenated castor oil) by the time of the CIR panel meeting. Their uses are expected to increase in the following years. The identified concentrations of PEG-60 hydrogenated castor oil in products are in the range of $0.00004 \%$ to $18 \%$, in which the maximum known concentration of $18 \%$ is contained in leave-in non-coloring hair products (18).

From the clinical reports of PEG-60 hydrogenated castor oil, a 27-year-old male patient with acute myeloblastic leukemia, receiving chemotherapy containing enocitabine, developed a high-grade fever and erythroblastopenia 6 hours after intravenous administration. PEG-60 hydrogenated castor oil was present in the enocitabine. A follow-up study evaluation of dosing enocitabine alone showed similar symptoms. When the patient's bone marrow was co-cultured with enocitabine or PEG-60 hydrogenated castor oil, significant growth inhibition of late erythroid progenitors was observed with the patient's IgG present. The researchers suggested that the immunological suppression effects of PEG-60 hydrogenated castor oil could be due to its hapten effect on the hypersensitive reaction of the patient's IgG (18). In another study, a 21-consecutive-day occlusive patch test was conducted for PEG-60 hydrogenated castor oil, with a $3 \%$ concentration in a formulation, in 12 human volunteers. Interestingly, the test concluded the formulation to be non-irritating (21). Thus, PEG-60 hydrogenated castor oil, when given according to the regulated dose, should be non-irritating to healthy consumers, while caution should be observed for individuals with immunosuppression or autoimmune syndromes.

Acute toxicity studies were conducted for PEG-60 hydrogenated castor oil in various animals including male and female Beagle dogs, male and female cynomolgus monkeys, male New Zealand white rabbits, male Hartley guinea pigs, and male S-D rats. Overall results showed systemic and irritant effects only in dogs, and not in the other animals tested, indicating species-specific effects (22).

Sub-chronic dermal toxicity studies of PEG-60 hydrogenated castor oil were conducted in 10 female ChR-CD rats through daily topical applications (5 times a week for 13 weeks) of 284 or $2,840 \mathrm{mg} / \mathrm{kg}$ of a formulation containing $3.0 \%$ PEG-60 hydrogenated castor oil. Treated sites showed slight erythema and dryness, but this was seen in both the experimental and control groups. Necropsy did not find any lesions, however significant hepatic weight and renal-tobody ratio changes were observed. Nevertheless, these changes were within the normal range of laboratory parameters, and no further histopathological changes were noted (Table 2) (29).

A sensitization study (similar methods to PEG-40 hydrogenated castor oil) in 102 human subjects with 3.0\% PEG60 hydrogenated castor oil formulation showed no sign of irritation in the subjects during the induction phase. During the challenge phase, only a doubtful reaction in one subject was observed after $48 \mathrm{hrs}$ of testing, which further showed negative results for sensitization during a follow-up test (Table 2) (27).

Genotoxicity studies were conducted for PEG-60 hydrogenated castor oil using a reverse mutation test in the Salmonella typhimurium strains TA100, TA98, TA1535, and TA1537, and in Escherichia coli strain WP2uvrA, with and without metabolic activation. Concentrations of the material tested ranged from 313 to $5,000 \mu \mathrm{g} /$ plate, and positive controls were used including 9-aminoacridine, sodium azide, 2-(2-furyl)-3-(5-nitro-2-furyl)-acrylamide, and 2aminoanthracene. Results showed no significant increase in revertant colony numbers at all concentrations, test strains, and metabolic conditions using PEG-60 hydrogenated castor oil, whereas genotoxic results were found in the positive controls. A chromosome aberration study was also conducted in Chinese hamster V79 cells using the same concentrations as mentioned above. Mitomycin $\mathrm{C}$ and dimethylnitrosamine were used as positive controls. Results showed a dose-dependent cell proliferation inhibition in the "without metabolic activation conditions" 24-48 hrs after treatment. The test material with metabolic activation showed only slight cell proliferation inhibition 6 hours after treatment, even at the highest dose. Overall, PEG-60 hydrogenated castor oil did not show chromosome aberrations under the experimental conditions, and it was concluded that the material was not genotoxic. Similar studies on the mouse micronucleus of 5 male and 5 female BDF1 mice were conducted by giving single intraperitoneal injections of $2,000 \mathrm{mg} / \mathrm{kg}$ bw dosage of PEG-60 hydrogenated castor oil to experimental groups, and saline or mitomycin $\mathrm{C}$ to the control groups. Bone marrow cells collected at 24, 48, and $72 \mathrm{hrs}$ post-treatment showed no relevant changes in micronucleated polychromatic or normochromatic erythrocytes. No signs of toxicity were observed, further supporting its non-genotoxic properties (Table 2) (30).

An ocular irritation test was also conducted for a $3.0 \%$ PEG-60 hydrogenated castor oil formulation, which caused minimal irritation to the eyes in 2 out of 6 rabbits tested after instillation. After $48 \mathrm{hrs}$, all signs had disappeared (Table 2) (28).

\section{CONCLUSIONS}

PEGs have a wide variety of PEG-derived mixtures due to their readily linkable terminal primary hydroxyl groups in combination with many possible compounds and complexes such as ethers, fatty acids, castor oils, amines, propylene glycols, among other derivatives. PEGs and their derivatives are broadly utilized in cosmetic products as surfactants, emulsifiers, cleansing agents, humectants, and skin conditioners. However, studies are lacking concerning those specific PEG-derived mixtures that we have evaluated in this review. Little is known about PEG/PPG-17/6 copoly- 
mer and PEG-20 glyceryl triisostearate, while some studies are available for PEG-40 hydrogenated castor oil and PEG60 hydrogenated castor oil as PEGylated oils, regarding their safety and toxicity in humans and animals. Reviews were mostly carried out on the general compound, with details in a few individual studies. Nevertheless, the present review summarizes the results of the known toxicity studies of these compounds in focus (Table 2).

PEG/PPG-17/6 copolymer has particularly little toxicological information, thus further investigation is obviously needed for it to be continually utilized in cosmetics and other products with human exposure. PEG-20 glyceryl triisostearate-related studies have shown an $\mathrm{LD}_{50}$ of $>2,000 \mathrm{mg} / \mathrm{kg}$ bw in rat acute oral studies. Furthermore, this compound was observed to be non-irritating to rabbit skin and eyes, non-sensitizing to guinea pig skin, and nonmutagenic (further details unknown). Both PEG-40 and PRG-60 hydrogenated castor oils were generally non-irritating and non-sensitizing to human skin up to $100 \%$ concentration. This was also supported by animal studies. Intravenous exposure to PEG-60 hydrogenated castor oil may cause hypersensitive or further immunosuppressive effects as found in a leukemia patient undergoing chemotherapy. Nevertheless, acute intravenous administration of PEG-60 hydrogenated castor oil to various animal species generally did not show toxic effects up to the highest administered dose of $100 \mathrm{mg} / \mathrm{kg}$. However, Beagle dogs showed some reactions that may show species-specific effects of PEG-60 hydrogenated castor oil. Repeated-dose toxicity with PEG40 hydrogenated castor oil in both S-D rats and Beagle dogs did not show toxic effects up to 64,000 -ppm and $5.0 \%$ dosage concentrations, respectively. Acute oral toxicity studies in rats of both PEG-40 and PEG-60 hydrogenated castor oils have shown $\mathrm{LD}_{50}$ values of $0.25 \%$ at $15.0 \mathrm{~g} / \mathrm{kg}$ and $3.0 \%$ at $5.0 \mathrm{~g} / \mathrm{kg}$, respectively. Sub-chronic dermal exposure of both mixtures to rats $(0.25 \%$ PEG- 40 and $0.3 \%$ PEG-60 hydrogenated castor oils) showed slight erythema (as well as in the controls), but did not cause any toxic effects. PEG-60 hydrogenated castor oil showed minimal eye irritation. PEG-60 hydrogenated castor oil was not genotoxic in bacteria or mammalian cells. Thus, these related PEGylated oils were concluded as safe for use in cosmetics according to regulating bodies and reviews found in this evaluation.

Unfortunately, no reliable safety or toxicity studies could be found for other PEG derivatives being evaluated in this review. Nevertheless, PEGs and PEG derivatives were generally regulated as safe for use in cosmetics, with the conditions that impurities and by-products, such as ethylene oxides and 1,4-dioxane, which are known carcinogenic materials, should be removed before they are mixed in cosmetic formulations. Ultimately, specific assessment studies for each chemical mixture are prompted for the exact evaluation of their safety in cosmetic use.

\section{ACKNOWLEDGMENT}

This work was supported by a grant from the Foundation of Korea Cosmetics Industry Institute in 2014.

\section{REFERENCES}

1. Polyethylene glycol: chemical product info at CHEMINDUSTRY.RU. Available from http://chemindustry.ru/Polyethylene_Glycol.php.

2. CIR Expert Panel. (2010) PEGs. Cosmetic Ingredient Review.

3. Fruijtier-Pölloth, C. (2005) Safety assessment on polyethylene glycols (PEGs) and their derivatives as used in cosmetic products. Toxicology, 214, 1-38.

4. European Parliament And Council Directive No 95/2/EC of 20 February 1995 on food additives other than colours and sweeteners. Available from Available from https://www.fsai.ie/ uploadedFiles/95_2_EC.pdf.

5. Lanigan, R.S., Yamarik, T.A. and Cosmetic Ingredient Review Expert Panel. (2001) Final report on the safety assessment of PEG-6, -8, and -20 sorbitan beeswax. Int. J. Toxicol., 20 Suppl 4, 27-38.

6. CIR Expert Panel. (2004) Final report of the amended safety assessment of PEG-5, -10, -16, -25, -30, and -40 soy sterol. Int. J. Toxicol., 23 Suppl 2, 23-47.

7. EWG (Environmental Working Group). Available from http:// www.ewg.org/skindeep/ingredient/704702/PEG\%3B\%3B_PPG$17 \% 3 \mathrm{~B} \% 3 \mathrm{~B} 6$ COPOLYMER/.

8. CIR Expert Panel. (2013) Safety assessment of alkyl PEGPPG ethers as used in cosmetics. Cosmetic Ingredient Review, Washington D.C., pp. 1-28.

9. SCCNFP. (1999) Opinion concerning Corrections in entries of poloxamers, meroxapols and poloxamines, and respective nomenclature conventions adopted by the plenary session of the SCCNFP on 17 February 1999. European Commission.

10. Singh-Joy, S.D. and McLain, V.C. (2008) Safety assessment of poloxamers $101,105,108,122,123,124,181,182,183$, $184,185,188,212,215,217,231,234,235,237,238,282$, 284, 288, 331, 333, 334, 335, 338, 401, 402, 403, and 407, poloxamer 105 benzoate, and poloxamer 182 dibenzoate as used in cosmetics. Int. J. Toxicol., 27 Suppl 2, 93-128.

11. Schmolka, I.R. (1994) Physical basis for poloxamer interactions. Ann. N. Y. Acad. Sci., 720, 92-97.

12. PEG/PPG-17/6 COPOLYMER Cosmetic Ingredient (INCI). Available from http://cosmetics.specialchem.com/inci/pegppg17-6-copolymer?id=9667.

13. PEG/PPG-17/6 copolymer-Cosmetic Ingredient Dictionary: Cosmetics Cop Expert Advice. Available from http:// www.paulaschoice.com/cosmetic-ingredient-dictionary/definition/pegppg-176- copolymer.

14. NICNAS (National Industrial Chemicals Notification And Assessment Scheme). (2010) FULL PUBLIC REPORT-PEG20 Glyceryl Triisostearate. NICNAS, pp. 1-7.

15. CIR Expert Panel. (2000) Final Report on the Safety Assessment of PEG-20 Sorbitan Cocoate; PEG-40 Sorbitan Diisostearate; PEG-2, -5, -20 Sorbitan Isostearate; PEG-40 and -75 Sorbitan Lanolate; PEG-10, -40, -44, -75, and -80 Sorbitan Laurate; PEG-3 and -6 Sorbitan Oleate; PEG-80 Sorbitan Pal- 
mitate; PEG-40 Sorbitan Perisostearate; PEG-40 Sorbitan Peroleate; PEG-3, -6, -40, and -60 Sorbitan Stearate, PEG-20, $-30,-40$, and -60 Sorbitan Tetraoleate; PEG-60 Sorbitan Tetrastearate; PEG-20 and -160 Sorbitan Triisostearate; PEG-18 Sorbitan Trioleate; PEG-40 and -50 Sorbitol Hexaoleate; PEG-30 Sorbitol Tetraoleate Laurate; PEG-60 Sorbitol Tetrastearate - Addendum to the Final Report on the Safety Assessment of Polysorbates. J. Am. Coll. Toxicol., IJT 19 Suppl. 2.

16. Johnson, W. Jr. and Cosmetic Ingredient Review Expert Panel. (2001) Final report on the safety assessment of trilaurin, triarachidin, tribehenin, tricaprin, tricaprylin, trierucin, triheptanoin, triheptylundecanoin, triisononanoin, triisopalmitin, triisostearin, trilinolein, trimyristin, trioctanoin, triolein, tripalmitin, tripalmitolein, triricinolein, tristearin, triundecanoin, glyceryl triacetyl hydroxystearate, glyceryl triacetyl ricinoleate and glyceryl stearate diacetate. Int.J. Toxicol., 20 Suppl 4, 61-94.

17. Lanigan, R.S., Yamarik, T.A. and Cosmetic Ingredient Review Expert Panel. (2002) Final report on the safety assessment of sorbitan caprylate, sorbitan cocoate, sorbitan diisostearate, sorbitan dioleate, sorbitan sesquiisostearate, sorbitan sesquistearate, and sorbitan triisostearate. Int. J. Toxicol., Suppl. 1, 93-112.

18. CIR Expert Panel. (2013) Final amended report, Amended Safety Assessment of PEGylated Oils as Used in Cosmetics. Cosmetic Ingredient Review.

19. BASF SE - Care Chemicals Division - Personal Care Ingredients. (2010) Cremohpor RH Grades.

20. CTFA (Cosmetic, Toiletry, and Fragrance Association). (1981) Clinical evaluation report: Human patch test of roll-on deodorant 20851-34 containing 0.25\% PEG-40 Hydrogenated Castor Oil.

21. Hill Top Research. (1976) The study of cumulative irritant properties of a series of test materials, 12G/66171-04, containing 3.0\% PEG-60 Hydrogenated Castor Oil (0547).

22. Hisatomi, A., Kimura, M., Maeda, M., Matsumoto, M.,
Ohara, K. and Noguchi, H. (1993) Toxicity of polyoxyethylene hydrogenated castor oil 60 (HCO-60) in experimental animals. J. Toxicol. Sci., 18 Suppl 3, 1-9.

23. CTFA (Cosmetic, Toiletry, and Fragrance Association). (1982) Acute oral toxicity of $2.5 \%$ PEG-40 Hydrogenated Castor Oil (RI 0538). No. 34-054.

24. CTFA (Cosmetic, Toiletry, and Fragrance Association). (1984) 13 week subchronic dermal toxicity study of formula 20851-34 containing 0.25\% PEG-40 Hydrogenated Castor Oil (RI 0538). CTFA, pp. 1-19.

25. Hua, L., Weisan, P., Jiayu, L. and Hongfei, L. (2004) Preparation and evaluation of microemulsion of vinpocetine for transdermal delivery. Pharmazie, 59, 274-278.

26. CTFA (Cosmetic, Toiletry, and Fragrance Association). (1976) Acute oral toxicity of 3.0\% PEG-60 Hydrogenated Castor Oil (RI 0538). CTFA.

27. CTFA (Cosmetic, Toiletry, and Fragrance Association). (1976) Allergic contact sensitization test of 12(3/66171-04 containing 3.0\% PEG-60 Hydrogenated Castor Oil. CTFA, pp. 1-9.

28. CTFA (Cosmetic, Toiletry, and Fragrance Association). (1976) Eye irritation of 3.0\% PEG-60 Hydrogenated Castor Oil RI 05471. No. 28-035.

29. CTFA (Cosmetic, Toiletry, and Fragrance Association). (1977) Thirteen week subacute dermal toxicity study in female ChR-CD rats, night cream containing 3.0\% PEG-60 Hydrogenated Castor Oil. CTFA, 1-9.

30. Hirai, O., Miyamae, Y., Zaizen, K., Miyamoto, A., Takashima, M., Hattori, Y., Ohara, K. and Mine, Y. (1994) Mutagenicity tests of polyoxyethylene hydrogenated castor oil 60 (HCO60). J. Toxicol. Sci., 19, 89-96.

31. Soliman, S.M., Abdel Malak, N.S., El-Gazayerly, O.N. and Abdel Rehim, A.A. (2010) Formulation of microemulsion gel systems for transdermal delivery of celecoxib: In vitro permeation, anti-inflammatory activity and skin irritation tests. Drug Discoveries Ther., 4, 459-471. 